\title{
Experimental Investigations of the NASA Common Research Model in the NASA Langley National Transonic Facility and NASA Ames 11-Ft Transonic Wind Tunnel (Invited)
}

\author{
Melissa B. Rivers ${ }^{*}$ \\ NASA Langley Research Center, Hampton, VA 23681 \\ Ashley Dittberner ${ }^{\dagger}$ \\ Jacobs Sverdrup, Hampton, VA 23681
}

\begin{abstract}
Experimental aerodynamic investigations of the NASA Common Research Model have been conducted in the NASA Langley National Transonic Facility and the NASA Ames 11-ft wind tunnel. Data have been obtained at chord Reynolds numbers of 5 million for five different configurations at both wind tunnels. Force and moment, surface pressure and surface flow visualization data were obtained in both facilities but only the force and moment data are presented herein. Nacelle/pylon, tail effects and tunnel to tunnel variations have been assessed. The data from both wind tunnels show that an addition of a nacelle/pylon gave an increase in drag, decrease in lift and a less nose down pitching moment around the design lift condition of 0.5 and that the tail effects also follow the expected trends. Also, all of the data shown fall within the 2-sigma limits for repeatability. The tunnel to tunnel differences are negligible for lift and pitching moment, while the drag shows a difference of less than ten counts for all of the configurations. These differences in drag may be due to the variation in the sting mounting systems at the two tunnels.
\end{abstract}

\section{Nomenclature}

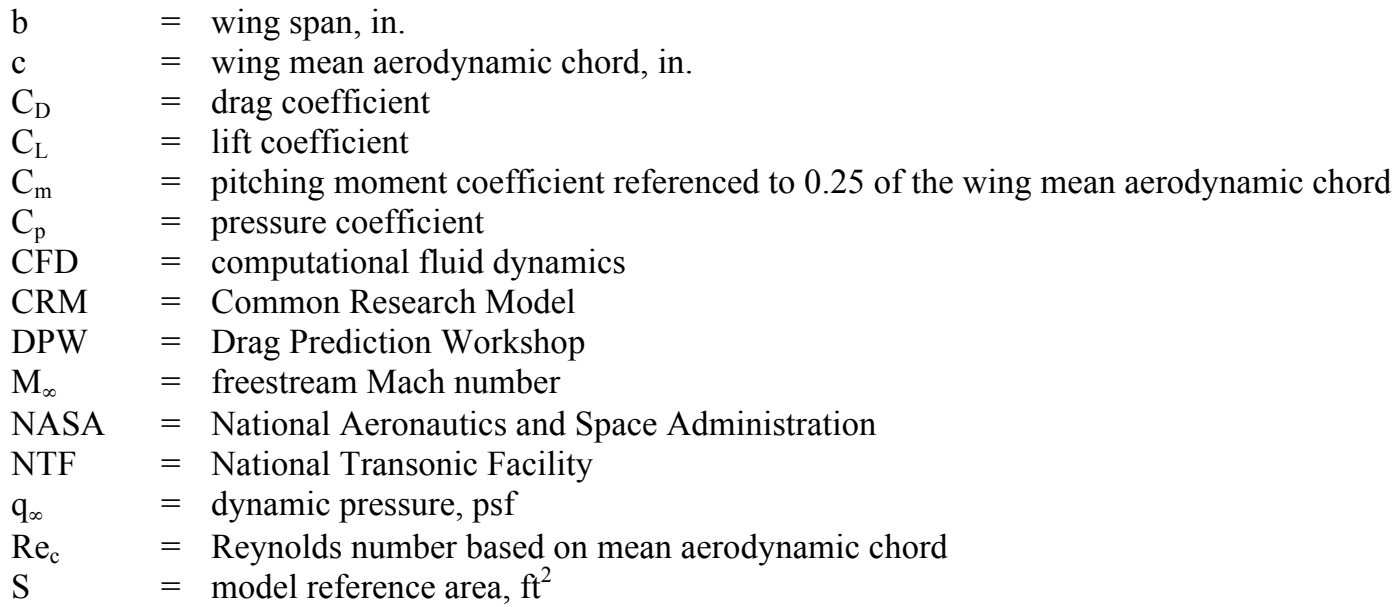

\footnotetext{
* Research Engineer, Configuration Aerodynamics Branch, Mail Stop 267, Senior Member AIAA

${ }^{\dagger}$ Test Engineer, ROME Group, Mail Stop 267, Senior Member AIAA
} 


$\begin{array}{ll}\text { TWICS } & =\text { Transonic Wall Interference Correction System } \\ \text { WB } & =\text { Wing } / \text { Body } \\ \text { WBPN } & =\text { Wing } / \text { Body } / \text { Pylon } / \text { Nacelle } \\ \text { WBT-2 } & =\text { Wing } / \text { Body } / \text { Tail }=-2^{\circ} \\ \text { WBT0 } & =\text { Wing } / \text { Body } / \text { Tail }=0^{\circ} \\ \text { WBT }+2 & =\text { Wing } / \text { Body } / \text { Tail }=+2^{\circ} \\ \text { WICS } & =\text { Wall Interference Correction System } \\ \text { x/c } & =\text { longitudinal distance from wing leading edge nondimensionalized by local wing } \\ & \text { chord } \\ \alpha & =\text { angle of attack, deg } \\ \eta & =\text { fraction of wing semi-span }\end{array}$

\section{Introduction}

$\mathrm{I}^{\mathrm{n}}$ an effort to assess the state of the art in computational fluid dynamics (CFD) drag prediction, the AIAA Applied Aerodynamics Technical Committee has initiated a series of Drag Prediction Workshops. The goal of the workshops is to assess state-of-the-art computational methods as practical aerodynamic tools for aircraft force and moment prediction of industry relevant geometries, with the focus being on drag prediction. The Drag Prediction Workshops (DPW) are designed to serve as an impartial forum for evaluating the effectiveness of existing computational Navier-Stokes solvers and modeling techniques. In addition, the DPW forum is intended to promote an open discussion on areas needing additional research and development. In order to encourage the widest participation, public-domain subject geometries have been used that are industry-relevant, yet simple enough to permit high-fidelity computations. Additionally, baseline grids have been provided with the intent of reducing the variability of CFD results.

The first drag prediction workshop ${ }^{1,2}$ (DPW-I), held in June of 2001, was directed at the calculation of a wing/body commercial transport configuration, known as the DLR-F4 ${ }^{3,4}$. Previously obtained experimental data were used as a reference for this first workshop. Predictions of a cruise polar and the drag rise were the focus. The second drag prediction workshop, ${ }^{5,6}$ (DPW-II), held in June of 2003, added the challenge of determining the increment due to adding a large component, in this case a pylon/nacelle. The DLR-F6 configuration ${ }^{5,7}$ was used for this study. Once again, experimental data were available for comparison. The third drag prediction workshop ${ }^{8,9}$ (DPW-III), held in June of 2006, added the challenge of determining the increment due to adding a small component, in this case a wing/body fairing. However for this workshop, the calculations were conducted "blind" with no experimental data available prior to the workshop. Force and moment, surface pressure, model deformation, and surface flow visualization data were obtained in an NTF wind tunnel investigation on the DLR-F6 configuration in the fall of $2007^{10}$. The fourth drag prediction workshop (DPW-IV), held in June of 2009, was another set of blind calculations. However for this workshop, the calculations were conducted on a brand new model called the Common Research Model (CRM). It is these "blind" calculations that draw the connection between the fourth drag prediction workshop and the current experimental investigations. The force and moment, surface pressure, model deformation, and surface flow visualization data obtained in these two wind tunnel investigations on the CRM and the results presented in this paper serve as the validation data for the calculations presented in the DPW-IV.

\section{Experimental Approach}

\section{A. Facility Description}

\section{National Transonic Facility}

The $\mathrm{NTF}^{11}$ is a unique national facility (Figure 1) that enables testing of aircraft configurations at conditions ranging from subsonic to low supersonic speeds at Reynolds numbers up to full-scale flight values. The NTF is a conventional, closed circuit, continuous-flow, fan-driven pressurized wind tunnel (Figure 2) capable of operating in either dry air at warm temperatures or nitrogen from warm to cryogenic temperatures. Elevated pressures in combination with cryogenic temperatures enable testing to the highest Reynolds numbers. The test section is 8.2 by 8.2 by $25 \mathrm{ft}$ and has a slotted floor and ceiling. In addition, four damping screens in the settling chamber and a contraction ratio of 14.95-to-1 reduce turbulence from the settling chamber to the nozzle throat. Fan-noise effects are minimized by acoustic treatment both upstream and downstream of the fan. Thermal insulation resides inside the pressure shell to aid in maintaining tunnel temperature and thus minimize energy consumption. 
The NTF has an operating pressure range of approximately 15 to 125 psia, a temperature range of -260 to $+120^{\circ} \mathrm{F}$, and a Mach number range of 0.2 to 1.2 . The maximum Reynolds number per foot is $146 \times 10^{6}$ at Mach 1 . When the tunnel is operated cryogenically, heat is removed by the evaporation of liquid nitrogen, which is sprayed into the tunnel circuit upstream of the fan. During this operational mode, venting is necessary to maintain a constant total pressure. When air is the test gas, heat is removed from the system by a water-cooled heat exchanger at the upstream end of the settling chamber. A mixed mode of operation can be used to reach higher Reynolds numbers. This mode uses liquid nitrogen to augment the cooling coil without the expense of fully crossing over into nitrogen mode. Further tunnel details and facility information are provided in Ref. 12.

\section{Ames 11-ft Transonic Wind Tunnel}

The Unitary Plan Wind Tunnel (UPWT) consists of three tunnel legs: the 11-By-11-Foot TWT, the 9- by 7-Foot Supersonic Wind Tunnel, and the 8- by 7-Foot Supersonic Wind Tunnel (Figure 3). The two supersonic legs share a common 11-stage axial-flow compressor and aftercooler drive leg, and they use diversion valves at the ends of a common drive leg. A three-stage axial-flow compressor drives the 11-By-11-Foot TWT. A common drive motor system can be coupled to either the 3-stage or 11-stage compressor. One tunnel can therefore be run while test articles are being installed in or removed from the other two.

The 11-By 11-Foot TWT leg, also known as the Ames 11-ft wind tunnel, is a closed-circuit, variable-pressure, continuous operation wind tunnel (Figure 4). Subsonic Mach number control involves setting the compressor drive speed to one of ten setpoints and using variable-camber inlet guide vanes for fine Mach number control. Supersonic Mach number control involves setting the flexible wall nozzle to achieve the proper area ratio in addition to setting the compressor drive speed and the inlet guide vanes. A tandem diffuser system with an annular diffuser followed by a wide-angle diffuser is upstream of a 70-ft-diameter aftercooler section in the drive leg. Flow-smoothing vanes are located in the tandem diffuser to improve flow uniformity entering the heat exchanger and temperature uniformity in the test section. The settling chamber upstream of the contraction is 38 feet in diameter. A Turbulence Reduction System (TRS) located in the settling chamber includes a 1-in.-cell-diameter, 20-in. long honeycomb for flow straightening followed by two 0.041-in.-diameter-wire, 6-mesh screens for turbulence reduction. The contraction provides a transition from the circular cross section of the settling chamber to the square cross section of the test section. The contraction ratio is 9.4. The test section is 11-By 11-feet in cross section and 22 feet in length. Slots in all four walls run the full length of the test section. The slots contain baffles that provide a 6-percent porosity into the plenum chamber. Ejector flaps on all four walls at the exit of the test section can be set remotely to control the plenum flow bypassed from the test section. Flow exits the test section and enters a transition region back to the circular main diffuser. A Plenum Evacuation System (PES) provides an active method of removing air from the test section plenum by using the Make-Up Air compressor system (MUA) of the auxiliaries facility. References 13 and 14 provide more detailed information about the Ames 11-ft wind tunnel.

\section{B. Model Description}

The model used in the current investigation was the NASA Common Research Model (CRM). This configuration consists of a contemporary supercritical transonic wing and a fuselage that is representative of a widebody commercial transport aircraft. The CRM is designed for a cruise Mach number of $\mathrm{M}_{\infty}=0.85$ and a corresponding design lift coefficient of $\mathrm{C}_{\mathrm{L}}=0.5$. A sketch of the CRM with reference quantities listed is shown in Figure 5. The aspect ratio is 9.0 , the leading edge sweep angle is $35 \mathrm{deg}$, the wing reference area (S) is $3.01 \mathrm{ft}^{2}$, the wing span (b) is 62.47 inches, and the mean aerodynamic chord (c) is 7.45 inches. The model moment reference center is located 35.8 inches back from the fuselage nose and 2.04 inches below the fuselage centerline. The nacelles used for this test were simple, flow through nacelles. Pressure distributions are measured on both the left and right wings using 291 pressure orifices located in 9 span-wise wing stations $(\eta=0.131,0.201,0.283,0.397,0.502,0.603$, $0.727,0.846$, and 0.950$)$ and on the left hand nacelle by 6 orifices at 6 radial stations $\left(\eta=30^{\circ}, 90^{\circ}, 150^{\circ}, 210^{\circ}, 270^{\circ}\right.$, and $330^{\circ}$ ). All pressure measurements were made using Electronically Scanned Pressure (PSP) modules mounted inside the forward portion of the fuselage. Based on quoted accuracies from the ESP module manufacturer, surface pressure measurements should be in error no more than $+/-0.015 \mathrm{psi}$. This in turn would correspond to a variation of no more than $+/-0.0026$ in terms of $\mathrm{Cp}$. The pressure measurements from this investigation are not presented herein but will be presented in a future publication. The model is mounted in the wind tunnel using a blade sting arrangement in both tunnels with the only differences occurring downstream of the model support system, as shown in figures 6 and 7 . No corrections have been made in either data set for this mounting arrangement.

Five different configurations were tested in the current investigation: the wing/body (WB) alone, wing/body/pylon/nacelle (WBPN), wing/body/tail $=0^{\circ}(\mathrm{WBT} 0)$, wing/body/tail $=+2^{\circ}(\mathrm{WBT}+2)$ and wing/body/tail $=-$ $2^{\circ}$ (WBT-2). Further details on this geometry are given in Ref. 15 . 


\section{Test Conditions}

\section{National Transonic Facility}

The investigation, conducted over a 6-week period, provided force and moment, surface pressure, model deformation, and surface flow visualization data. Testing was conducted at 5, 19.8 and 30 million Reynolds number. The 5 and 19.8 million Reynolds number data were collected to provide a comparison to previously calculated CFD results and all of the Reynolds numbers were used to provide an assessment of Reynolds number effects. The 19.8 million Reynolds number data were collected at two different $\mathrm{q}_{\infty}$ levels - a high and a low $\mathrm{q}_{\infty}$ condition. Having two $\mathrm{q}_{\infty}$ levels at the same Reynolds number provides an aeroelastic step in the data. All Reynolds number values presented in this paper are based on mean aerodynamic chord. The data were collected at temperatures ranging from $-250^{\circ} \mathrm{F}$ up to $120^{\circ} \mathrm{F}$. For the comparisons made in this paper, only the $\mathrm{Re}_{\mathrm{c}}=5$ million data obtained at a temperature of $120^{\circ} \mathrm{F}$ are presented.

All data presented in this paper were obtained at freestream Mach numbers ranging from 0.7 to 0.87 . Data were generally obtained over an angle-of-attack range from $-3^{\circ}$ to $+12^{\circ}$ at 5 million Reynolds number and from $-3^{\circ}$ to $+6^{\circ}$ at 19.8 and 30 million Reynolds numbers. The reduced angle-of-attack range at the higher Reynolds number was required such that safe model stress levels would not be exceeded. Flow angularity measurements were made and upflow corrections ranging from $0.092^{\circ}$ to $0.173^{\circ}$ were applied to the final NTF data. Classical wall corrections accounting for model blockage, wake blockage, tunnel buoyancy, and lift interference have been applied according to the methods presented below. Testing on the WBPN, WBT +2 and WBT-2 configurations was conducted at a Reynolds number of 5 million only. However, data were obtained at all three Reynolds numbers for both the WB and WBT0 configurations.

In order to ensure a consistent and repeatable transition from laminar to turbulent flow and to support the goal of the wind tunnel data being used for CFD validation purposes, it was important to apply a proven and reliable method to fix transition on the model. Evercoat trip dots measuring 0.05 inches in diameter and spaced 0.1 inches apart (center to center) were used for the current investigation. For a chord Reynolds number of 5 million, a trip dot height of 0.0035 inches was used from the SOB (side of body) to the yehudi break, 0.003 inches was used from the yehudi break to the midwing and 0.003 inches was used from the midwing to the wing tip. These trip dots were installed at $10 \%$ chord. Vinyl adhesive trip dots were applied at the nose of the fuselage and left on for the entire test. When the nacelles were on the model, trip dots were located 0.43 inches back from the leading edge on the outer surface and the inner surface. Finally, when the tails were on the model, trip dots were located at $10 \%$ chord and measured 0.003 inches.

Another important set of data obtained in this investigation was model deformation measurements. Since an effective correlation of computational and experimental data will be directly tied to how well the computational and experimental model geometries match one another, it is important to obtain an accurate definition of the model geometry as tested under aerodynamic loads. In order to obtain this information a video model deformation measurement technique ${ }^{16}$ has been developed and employed multiple times at the NTF. This system was used in the current investigation to obtain wing deflection and twist measurements due to aerodynamic loading but the data is not presented herein.

\section{Ames 11-ft Wind Tunnel}

The investigation, conducted over a 5-week period, provided force and moment, surface pressure, and surface flow visualization data. Testing was conducted at a chord Reynolds number of 5 million. The data were collected at temperatures of approximately $100^{\circ} \mathrm{F}$.

All data presented in this paper were obtained at freestream Mach numbers ranging from 0.7 to 0.87 . Data were generally obtained over an angle-of-attack range from $-3^{\circ}$ to $+12^{\circ}$ at 5 million chord Reynolds number. Flow angularity measurements were made and upflow corrections ranging from $0.013^{\circ}$ to $0.067^{\circ}$ were applied to the final data. Classical wall corrections accounting for tunnel buoyancy and lift interference have been applied according to the method presented below.

Transition was also fixed on the model when tested at the Ames 11-ft wind tunnel. For this investigation, though, only vinyl adhesive trip dots were applied. These trip dots measured 0.05 inches in diameter and were spaced 0.1 inches apart. For a chord Reynolds number of 5 million, a trip dot height of 0.0035 inches was used from the SOB (side of body) to the yehudi break, 0.003 inches was used from the yehudi break to the midwing and 0.003 inches was used from the midwing to the wing tip. These trip dots were installed at $10 \%$ chord. Vinyl adhesive trip dots were also applied at the nose of the fuselage and left on for the entire test. When the nacelles were on the model, trip dots were located 0.43 inches back from the leading edge on the outer surface and the inner surface. Finally, when the tails were on the model, trip dots were located at $10 \%$ chord and measured 0.003 inches. 


\section{Wall Correction Methods for NTF and Ames 11-ft Wind Tunnels}

Both the NTF and the Ames 11-ft wind tunnels use the Transonic Wall Interference Correction System (TWICS) to provide blockage and incidence corrections due to the presence of the test section boundary. TWICS and its predecessor, the Wall Interference Correction System (WICS), were developed at the NASA Ames Research Center by Ulbrich et al. ${ }^{17-24}$ as a modification and extension of the Hackett wall signature method. ${ }^{25-29}$ TWICS is an enhanced version of WICS that handles ventilated boundary conditions, typically seen in transonic wind tunnels. This method was chosen to be implemented at the NTF, see Iyer et al., ${ }^{30,31}$ in an effort to standardize the wall interference correction methodology across NASA centers. TWICS is based on a linearized potential flow method with a Prandtl-Glauert compressibility model which inherently assumes that there is a portion of flow in the test section between the near-field region of the test article and the near-field region of the wall that is a linear perturbation of the empty test section flow field.

The method uses a tared wall pressure signature, which is the difference between the model installed condition and the empty test section, a database of normalized perturbation velocities using unit singularity solutions computed for a given mathematical representation of the wall boundary condition, and geometric information from the test article. Tareing of the wall pressure signature is performed to remove first order effects of the empty tunnel boundary layer and buoyancy, is assumed to contain only the solid and wake blockage, and is also assumed that the additional second order change in the test-section-wall boundary layer displacement thickness due to the presence of the test article is negligible - an assumption that is violated by flow near a Mach number of unity where aspects of the crossflow are more critical. The test article is modeled with an appropriately weighted point doublet chain ${ }^{32}$ to represent the fuselage, wake, and support system. Line doublets, typically distributed along the lifting surface quarter-chord, are used to simulate the effect of lift. The strengths of the line doublets are determined using the measured lift from the balance. The resulting wall signature from these singularities is subtracted from the tared wall signature, leaving only the blockage signature. This remaining signature is used to determine the strengths of the solid and wake blockage singularities.

Although both facilities use TWICS, the implementations are not identical. The differences occur in how the wall boundary conditions are formulated and applied. Ulbrich ${ }^{23,24}$ performed a calibration and validation of the baffled, slotted (i.e. porous) wall boundary condition for the Ames 11-ft wind tunnel. Walker ${ }^{33}$ calibrated and validated the longitudinal slotted wall boundary condition in the NTF. A discrete wall formulation, where the boundary condition is applied in the baffled slot, is used at the Ames 11-ft wind tunnel; whereas, a homogeneous wall formulation, which is more of an averaged representation of the effect of the ventilated wall boundary, is used at the NTF. Work is in progress to assess the impact of modeling the NTF wall boundary condition as discrete. It is anticipated that a change to the discrete formulation of the NTF may lead to a decreased incidence correction. Data presented in this paper are corrected using the respective implementations of TWICS at each facility.

\section{Results and Discussion}

\section{A. Pylon/Nacelle effects}

Determining the effects of adding a nacelle/pylon to the configuration was one goal of the current investigations. Figures $8-10$ show these effects at Mach 0.7, 0.85 and 0.87, respectively, for both wind tunnels. Figure 8 indicates that at Mach 0.7, the addition of a nacelle/pylon increases the drag, lowers the lift and gives a less nose down pitching moment at $C_{L}=0.5$ for both wind tunnels. The actual values for lift and pitching moment give a negligible difference between the wind tunnel tests. For the drag, though, there is approximately a three drag count difference for the WB configuration and a five drag count difference for the WBPN configuration between the wind tunnels. In figure 9 it is shown that the drag increases, the lift lowers and the pitching moment is less nose down at $C_{L}=0.5$ and Mach $=0.85$ with the addition of a nacelle/pylon in both wind tunnels. The slopes are the same for lift, drag and pitching moment with negligible differences in the values of lift and pitching moment between the wind tunnels. At $\mathrm{M}=0.85$, there is approximately a seven drag count difference for both the WB and WBPN configurations between the wind tunnels. Finally, figure 10 shows that for a Mach number of 0.87 , the drag increases, the lift decreases and the pitching moment is less nose down for a $\mathrm{C}_{\mathrm{L}}=0.5$ with a nacelle/pylon added in both wind tunnels. At $\mathrm{M}=0.87$, the data show the same slopes for lift and pitching moment with a negligible difference in the actual values for both wind tunnels. The drag curve shows the same slope for both configurations with almost no difference in drag for the WB configuration and a ten drag count difference between the wind tunnels for the WBPN configuration. 


\section{B. Tail Effects}

Another goal of these investigations was to determine the tail effects for the CRM model. Three different tail settings were tested at both wind tunnels - tail $=-2^{\circ}$, tail $=+2^{\circ}$ and tail $=0^{\circ}$, on the wing/body configuration. All of these cases were run at a chord Reynolds number of 5 million. Figures $11-13$ show the tail effects for Mach $=0.7$, 0.85 and 0.87 , respectively. In figure 11 we see that going from a $-2^{\circ}$ to a $+2^{\circ}$ tail setting shows a decrease in drag, an increase in lift and an increase in nose-down pitching moment, as expected, for the $\mathrm{C}_{\mathrm{L}}=0.5$ and $\mathrm{M}=0.7$ condition. The actual values for lift and pitching moment indicate a negligible difference between the wind tunnel tests while there is an approximate variation of seven drag counts for the WBT-2 setting and a variation of approximately five drag counts for the WBT0 and WBT +2 settings. Figure 12 shows that for the $\mathrm{C}_{\mathrm{L}}=0.5$ and $\mathrm{M}=$ 0.85 condition, there is again a decrease in drag, an increase in lift and an increase in nose down pitching moment when going from $\mathrm{a}-2^{\circ}$ to $\mathrm{a}+2^{\circ}$ tail setting for both wind tunnels, with negligible difference between the wind tunnel lift and pitching moment actual values. The drag values give a difference of approximately five drag counts for the WBT-2 setting and a difference of approximately seven drag counts for the WBT0 and WBT +2 settings. As shown in figure 13, at $\mathrm{M}=0.87$ both wind tunnels show that going from a $-2^{\circ}$ to a $+2^{\circ}$ tail setting again gives an increase in drag, an increase in lift and an increase in nose-down pitching moment with negligible difference in actual values for drag, lift and pitching moment.

\section{Data Repeatability}

When data are obtained in any experimental investigation it is important to make an assessment of data accuracy or data repeatability. In order to make such an assessment for the current investigation, multiple repeat runs were obtained for all five of the configurations in both wind tunnels. To obtain the most reliable assessment of data repeatability it is best to have the repeat runs distributed widely throughout the duration of the investigation. Unfortunately this process is usually in conflict with an efficient execution of the test plan. Keeping these thoughts in mind, the following sets of repeat runs were obtained. Within each series of runs, 3 runs were obtained at $\mathrm{M}_{\infty}=$ 0.7 and 0.85 . Each of these 3 runs were always separated by at least one run at a different test condition. This resulted in 3 repeat runs for the all of the configurations at all of the conditions listed above. The repeatability data resulting from these runs at a $\mathrm{M}=0.85$ only are presented in figures $14-23$. Delta coefficient data are presented versus angle of attack for each configuration at each condition. The delta coefficient data presented represent the difference between the coefficient value measured and the average value of the coefficient at that particular angle of attack. These delta coefficient, or residual, data show the level of variation in the repeat runs. The solid lines shown on each plot indicate the 2-sigma limits based on all the data across the angle-of-attack range. Thus it is shown that essentially all the residual data fall within the 2-sigma limits.

\section{Summary}

A successful investigation of the new NASA Common Research Model has been completed in the National Transonic Facility and the Ames 11-ft Wind Tunnel. Data have been obtained at chord Reynolds numbers of 5 million for the WB, WBPN, WBT0, WBT +2 and WBT-2 configurations. Force and moment, surface pressure and surface flow visualization data were obtained but only the force and moment data are presented herein. Nacelle/pylon, tail effects and tunnel-to-tunnel effects have been assessed.

1) The addition of a nacelle/pylon gave an increase in drag, decrease in lift and a less nose down pitching moment around the design lift condition of 0.5 at both wind tunnels.

2) The tail effects follow the expected trends at both wind tunnels.

3) The between tunnel comparisons showed a negligible difference in lift and pitching moment values and less than ten drag count difference for any of the configurations in drag.

4) All of the data shown fall within the 2-sigma limits for repeatability.

\section{Acknowledgments}

The authors would like to gratefully acknowledge the efforts of the NASA team throughout all phases of this experimental investigation. NTF and Ames 11-ft staff are recognized for their efforts in effectively obtaining all desired experimental data. The supportive discussions with the DPW committee prior to and throughout the wind tunnel investigation are also acknowledged. 


\section{References}

${ }^{1 .}$ Levy, D. W., Vassberg, J. C., Wahls, R. A., Zickhur, T., Agrawal, S., Pirzadeh, S., and Hemsch, M. J., "Summary of Data from the First AIAA CFD Drag Prediction Workshop," AIAA Paper 2002-0841, January 2002.

2. Hemsch, M. J., "Statistical Analysis of CFD Solutions from the Drag Prediction Workshop," AIAA Paper 2002-0842, January 2002.

${ }^{3 .}$ Redeker, G., Schmidt, N., and Muller, R., "Design and Experimental Verification of a Transonic Wing for a Transport Aircraft," Proceedings of the FDP Symposium on Subsonic/Transonic Configuration Aerodynamics, AGARD CP 285 , 1980, pp. 13.1-13.7.

4. Redeker, G., "DLR-F4 Wing Body Configuration," A Selection of Experimental Test Cases for the Validation of CFD Codes, AGARD Report AR-303, Vol. 2, 1994, pp. B4-1-21.

${ }^{5 .}$ Laflin, K. R., Vassberg, J. C., Wahls, R. A., Morrison, J. H., Brodersen, O., Radowitz, M., Tinoco, E. N., and Godard, J., "Summary of Data from the Second AIAA CFD Drag Prediction Workshop," AIAA Paper 2004-0555, January 2004.

${ }^{6 .}$ Hemsch, M. J. and Morrison, J. H., "Statistical Analysis of CFD Solutions from the 2nd Drag Prediction Workshop," AIAA Paper 2004-0556, January 2004.

7. Rossow, C.-C., Godard, J.-L., Hoheisel, H., and Schmitt, V., "Investigations of Propulsion Integration Interference Effects on a Transport Aircraft Configuration," Journal of Aircraft, Vol. 31, No. 5, 1994, pp. 1022-1030.

${ }^{8 .}$ Vassberg, J. C., Tinoco, E. N., Mani, M., Broderson, O. P., Eisfeld, B., Wahls, R. A., Morrison, J. H., Zickuhr, T., Laflin, K. R., and Mavriplis, D. J., "Summary of the Third AIAA CFD Drag Prediction Workshop," AIAA Paper 2007-0260, January 2007.

${ }^{9}$ Morrison, J. H. and Hemsch, M. J., "Statistical Analysis of CFD Solutions from the Third AIAA Drag Prediction Workshop," AIAA Paper 2007-0254, January 2007.

10. Gatlin, G. M., Rivers, M.B., Goodliff, S. L., Rudnik, R., and Sitzmann, M., "Experimental Investigation of the DLR-F6 Transport Configuration in the National Transonic Facility (invited)," AIAA Paper 2008-6917, August 2008.

11. Gloss, B. B., "Current Status and Some Future Test Directions for the US National Transonic Facility. Wind Tunnels and Wind Tunnel Test Techniques," Royal Aeronautical Society, 1992, pp. 3.1-3.7.

12. Fuller, D. E., "Guide for Users of the National Transonic Facility," NASA TM-83124, 1981.

13. Kmak, F., "Modernization and Activation of the NASA Ames 11-By-11-Foot Transonic Wind Tunnel," AIAA Paper 2000-2680, June 2000 .

14. Amaya, M.A. and Murthy, S.V., "Flow Quality Measurements in the NASA Ames Upgraded 11-By-11-Foot Transonic Wind Tunnel (invited Paper)," AIAA Paper 2000-2681, June 2000.

15. J. C. Vassberg, M. A. DeHaan, S. M. Rivers, and R. A. Wahls. "Development of a Common Research Model for Applied CFD validation studies." AIAA Paper 2008-6919, 26th AIAA Applied Aerodynamics Conference, Hawaii, HI, August 2008.

16. Burner, A. W. and Liu, T., "Videogrammetric Model Deformation Measurement Technique," Journal of Aircraft, Vol. 38, No. 4, July-August 2001, pp. 745-754.

17. Ulbrich, N. and Lo, C., "A Wall Interference Assessment/Correction System," Semi-Annual Report \#1, The University of Tennessee Space Institute, December 1991.

18. Ulbrich, N., Lo, C., and Steinle, Jr., F., "Blockage Correction in Three-Dimensional Wind Tunnel Testing Based on the Wall Signature Method," July 6-8 1992, Presented at the AIAA 17th Aerospace Ground Testing Conference, AIAA Paper 92-3925.

19. Ulbrich, N. and Steinle, Jr., F., "Real-Time Wall Interference Calculation in Three-Dimensional Subsonic Wind Tunnel Testing," January 10-13 1994, Presented at the 32nd Aerospace Sciences Meeting and Exhibit, AIAA Paper 94-0771.

20. Ulbrich, N. and Steinle, Jr., F., "Semispan Model Wall Interference Prediction Based on the Wall Signature Method," January 9-12 1995, Presented at the 33rd Aerospace Sciences Meeting and Exhibit, AIAA Paper 95-0793.

21. Ulbrich, N. and Boone, A., Real-Time Wall Interference Correction System of the 12FT Pressure Wind Tunnel," January 12-15 1998, Presented at the 36th Aerospace Sciences Meeting and Exhibit, AIAA Paper 98-0707.

22. Ulbrich, N., "The Real-Time Wall Interference Correction System of the NASA Ames 12-Foot Pressure Tunnel," NASA CR 1998-208537, 1998.

23. Ulbrich, N. and Boone, A., "Determination of the Wall Boundary Condition of the NASA Ames 11FT Transonic Wind Tunnel," January 8-11 2001, Presented at the 39th Aerospace Sciences Meeting and Exhibit, AIAA Paper 2001-1112.

24. Ulbrich, N. and Boone, A., "Direct Validation of the Wall Interference Correction System of the Ames 11-Foot Transonic Wind Tunnel," May 2003, NASA/TM-2003-212268.

25. Hackett, J. and Wilsden, D., "Determination of Low Speed Wake Blockage Corrections Via Tunnel Wall Static Pressure Measurements," Wind Tunnel Design and Testing Techniques, March 1976, AGARD-CP-174. Presented to the AGARD

Fluid Dynamics Panel Symposium on Wind Tunnel Design and Testing Techniques: London, England, 6-8 October 1975.

26. Hackett, J. and Boles, R., "Wake Blockage Corrections and Ground Effect Testing in Closed Wind Tunnels," Journal of Aircraft, Vol. 13, No. 8, August 1976, pp. 597ñ604.

27. Hackett, J. and Wilsden, D., "Estimation of Wind Tunnel Blockage from Wall Pressure Signatures: A Review of Recent Work at Lockheed-Georgia," AIAA Paper 78-828, April 1978. 
28. Hackett, J., Wilsden, D., and Lilley, D., "Estimation of Tunnel Blockage from Wall Pressure Signatures: A Review and Data Correlation," NASA CR 15224, March 1979.

29. Hackett, J., Wilsden, D., and Stevens, W., “A Review of the 'Wall Pressure Signature' and Other Tunnel Constraint Correction Methods for High Angle-of-Attack Tests," AGARD R692, February 1981, Presented to the AGARD Fluid Dynamics Panel Round Table Discussion on Wind Tunnel Corrections for High Angle-of-Attack Models: Munich, FRG, 8 May 1980.

30. Iyer, V., Everhart, J., Bir, P., and Ulbrich, N., "Implementation of the WICS Wall Interference Correction System at the National Transonic Facility," June 19-22 2000, Presented at the 21st AIAA Aerodynamic Measurement Technology and Ground Testing Conference, Denver, CO, AIAA Paper 2000-2383.

31. Iyer, V. and Everhart, J., "Application of Pressure-Based Wall Correction Methods to Two NASA Langley Wind Tunnels," June 11-14 2001, Presented at the 19th AIAA Applied Aerodynamics Conference, Anaheim, CA, AIAA Paper 2001-2472.

32. Ulbrich, N., "The Representation of Wind Tunnel Model Blockage Effects Using Point Doublets," January 14-17 2002, Presented at the 40th Aerospace Sciences Meeting and Exhibit, AIAA Paper 2002-0880.

33. Walker, E., Statistical Calibration and Validation of a Homogeneous Ventilated Wall-Interference Correction Method for the National Transonic Facility, Ph.D. thesis, Virginia Polytechnic Institute and State University, October 2005, Available electronically at http://scholar.lib.vt.edu/theses/available/etd-10272005-165559/. Also available as NASA/TP 2005213947, 2005. 


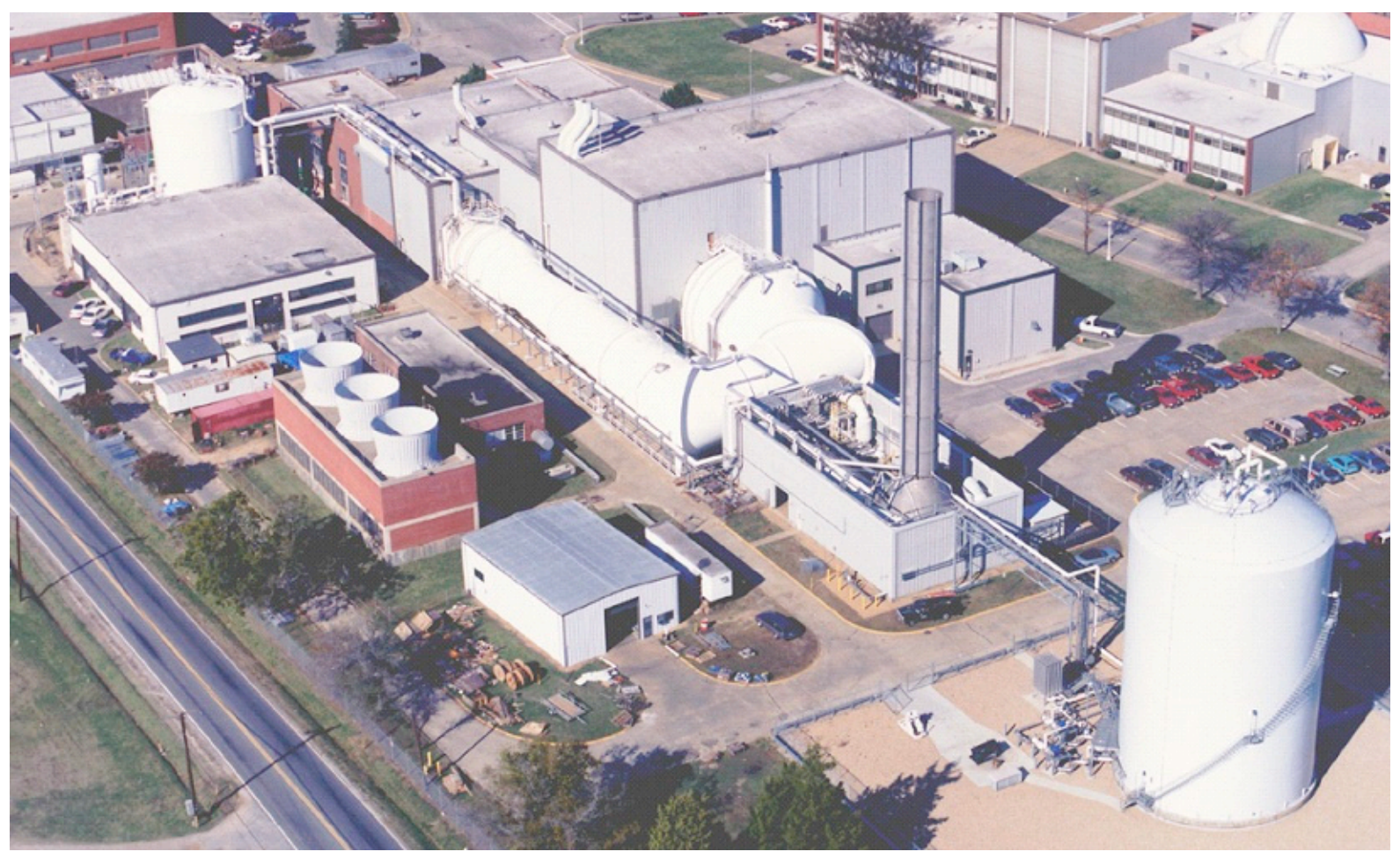

Figure 1. Aerial View of the National Transonic Facility.

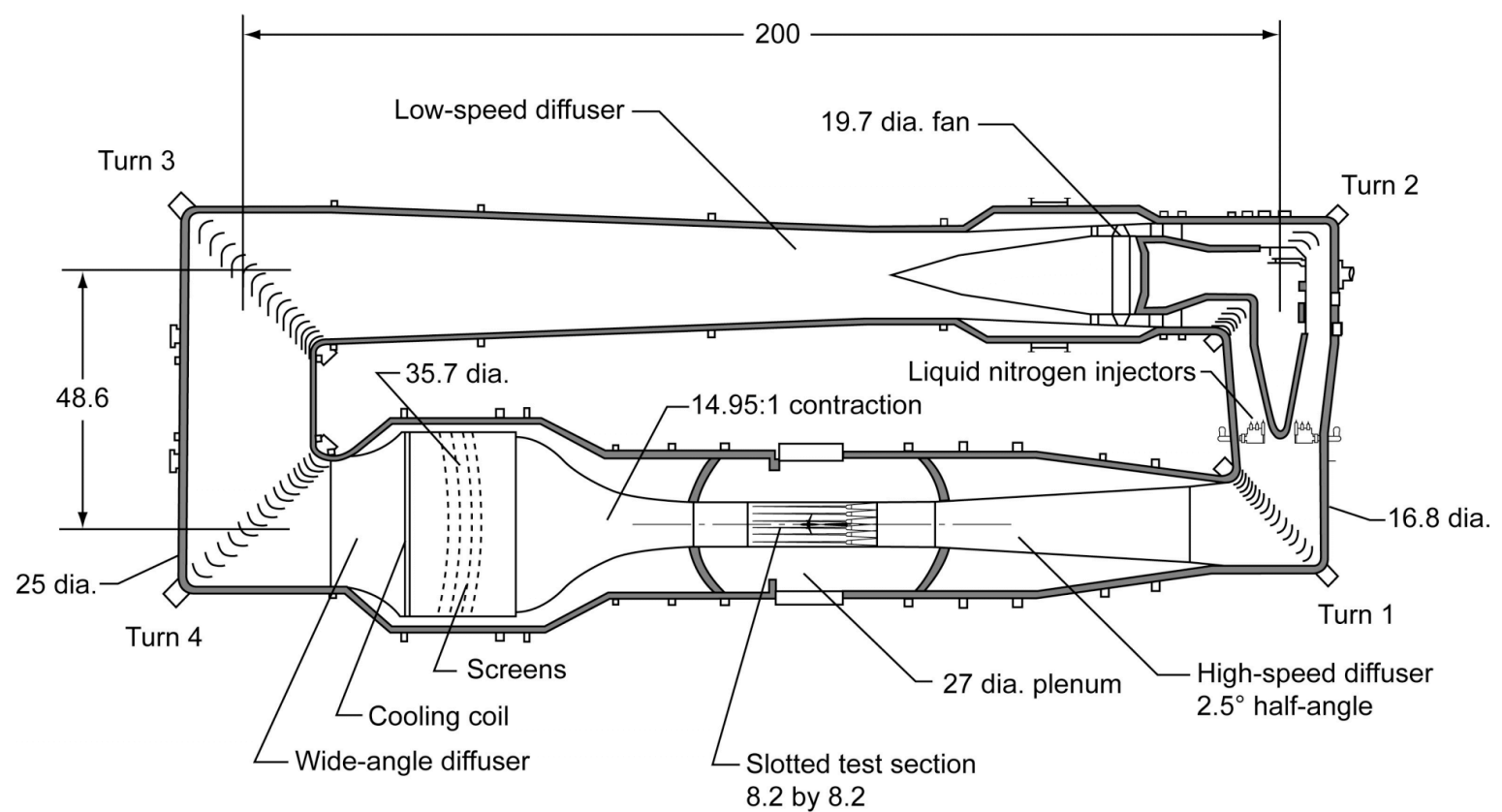

Figure 2. Sketch of the National Transonic Facility tunnel circuit. Linear dimensions are given in feet. 


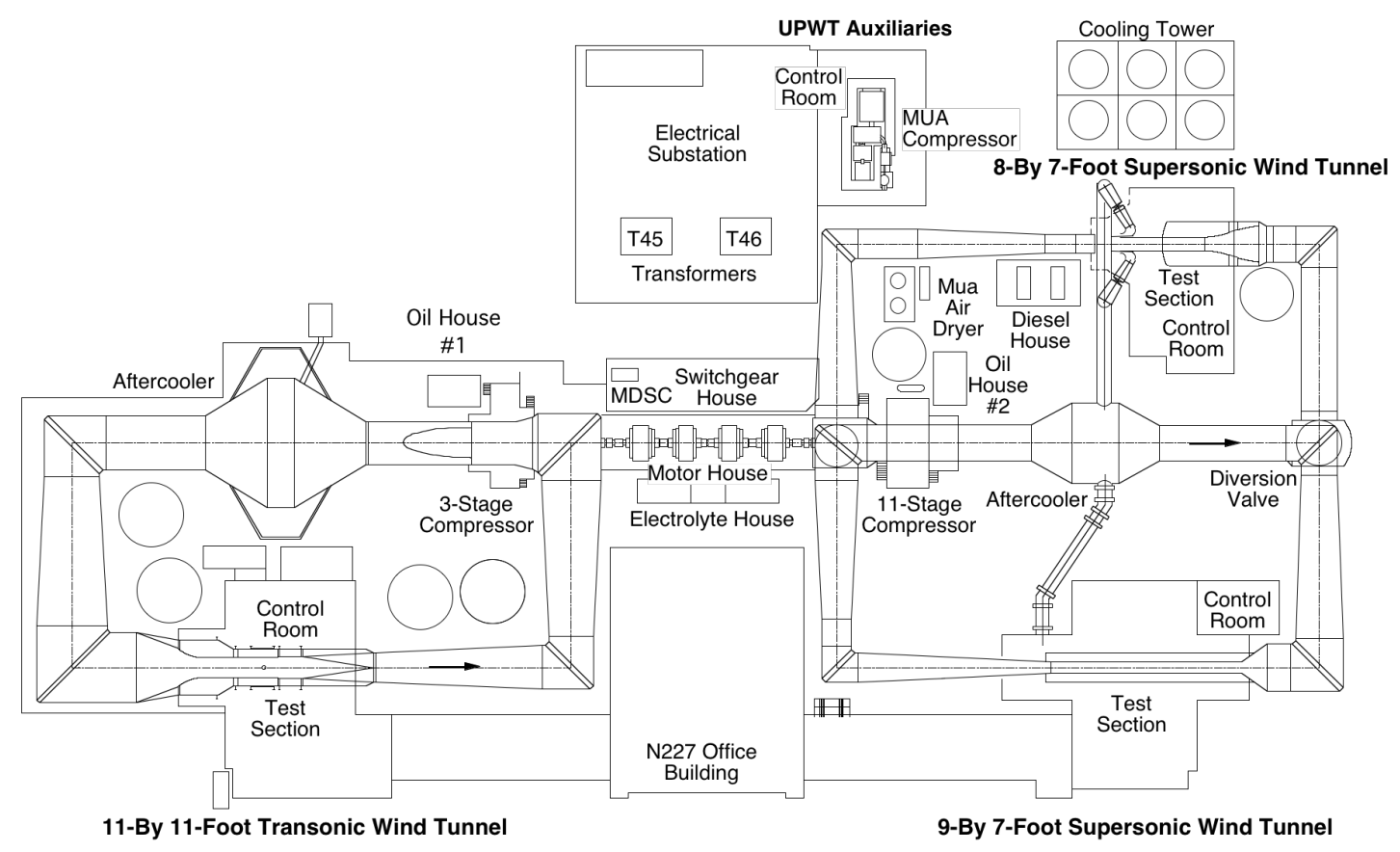

Figure 3. Unitary Plan Wind Tunnel (UPWT) At the NASA Ames Research Center.

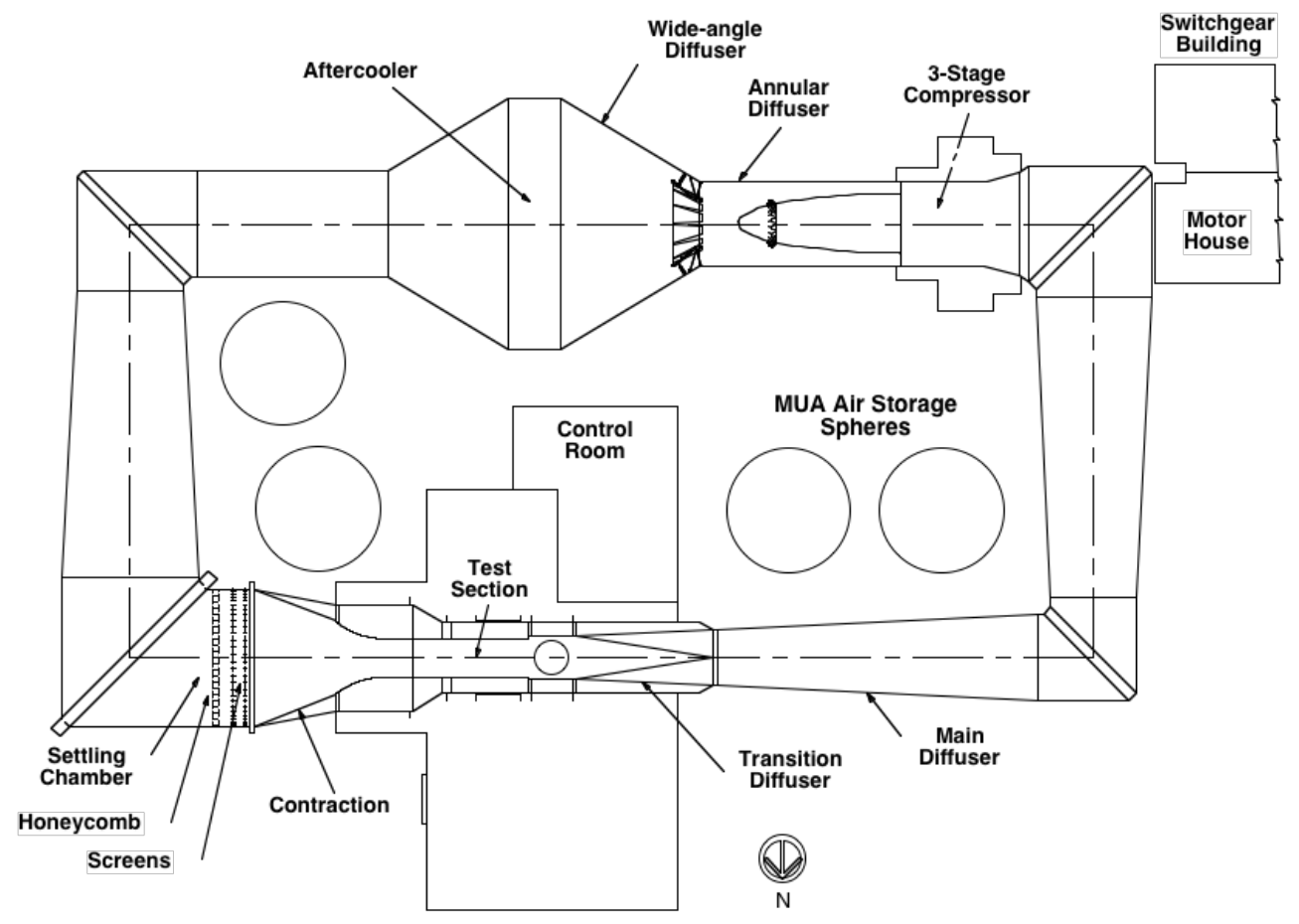

Figure 4. Sketch of the Ames 11-Foot Wind Tunnel.

10

American Institute of Aeronautics and Astronautics 


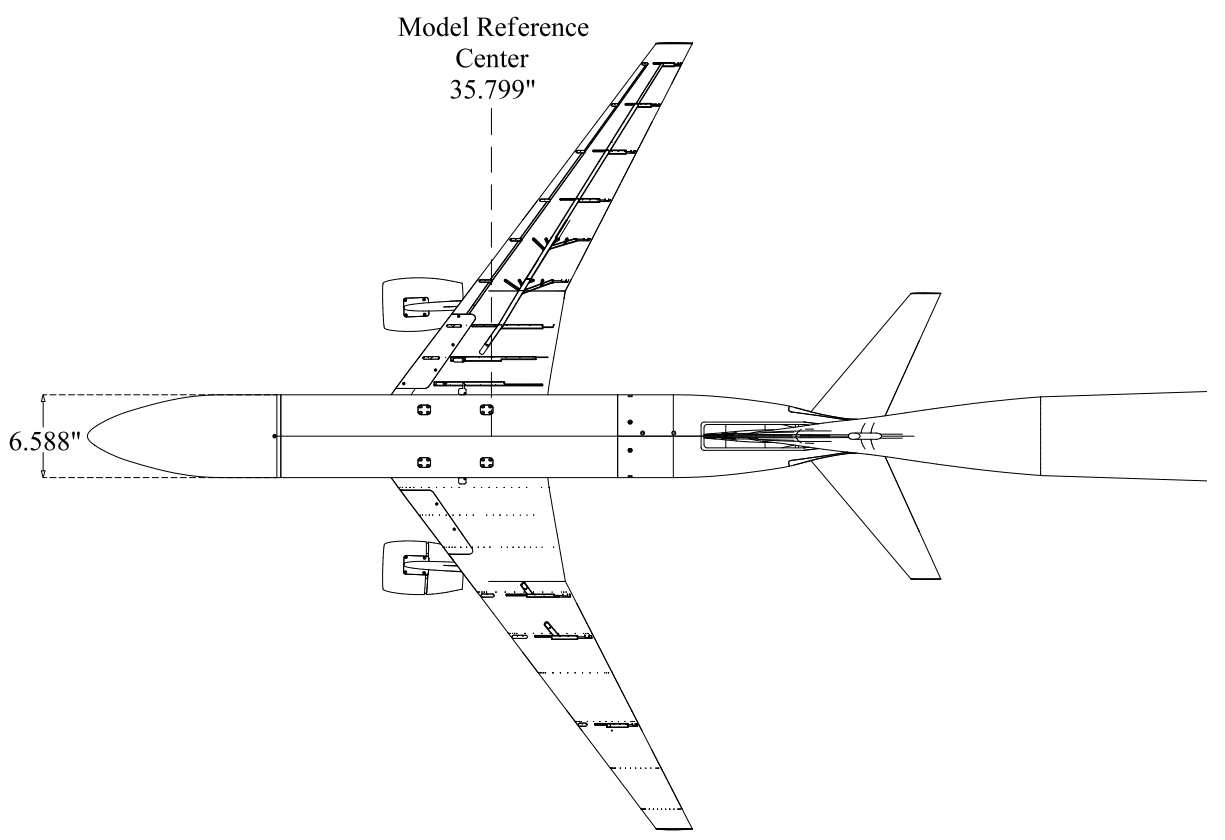

a) Top View

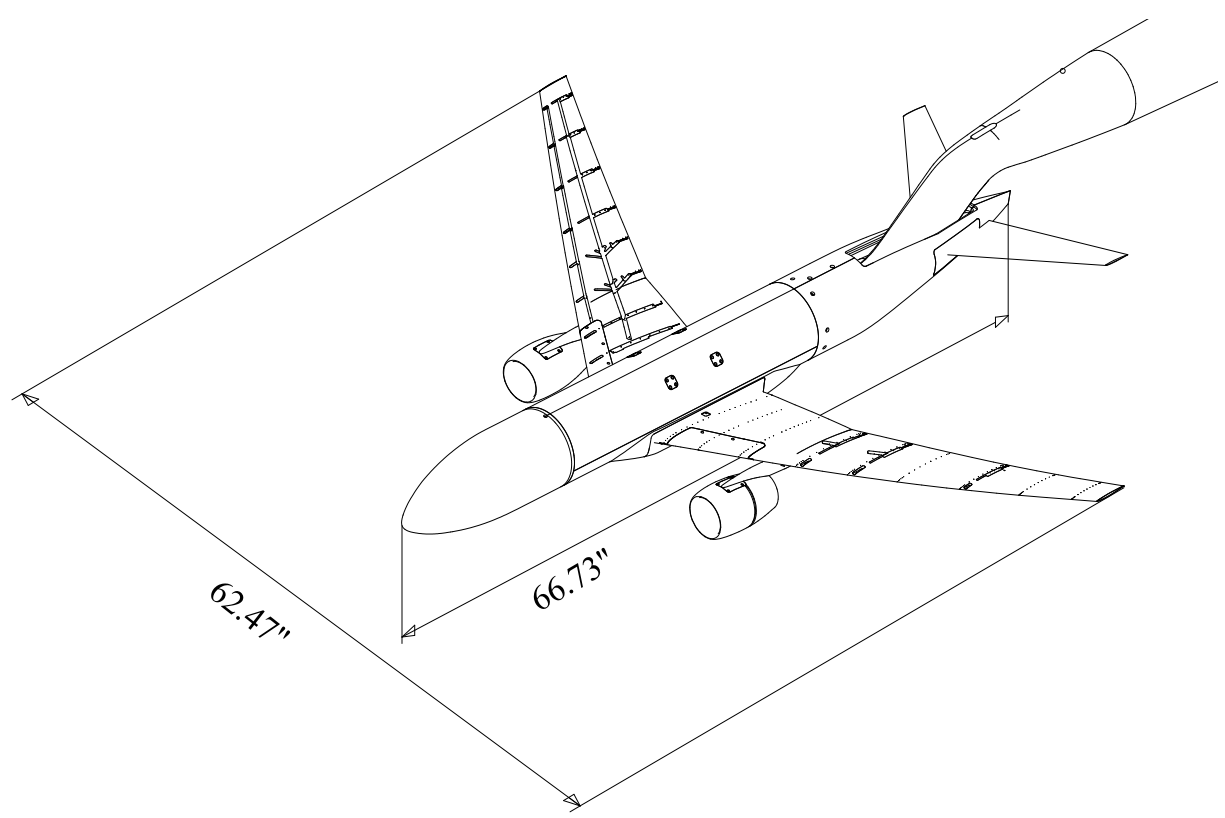

b) Isometric View

Figure 5. Sketch of the Common Research Model with Reference Quantities. 


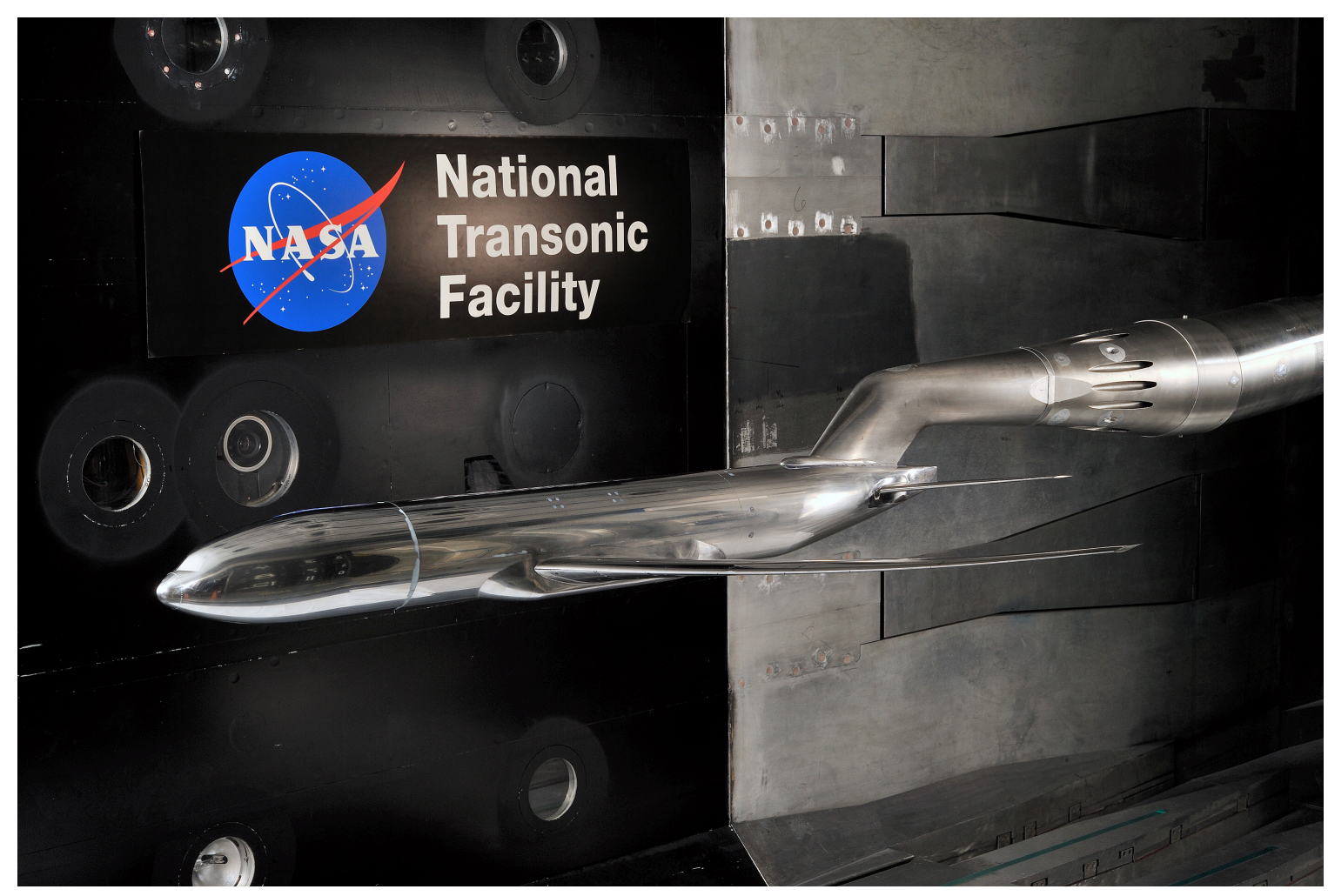

Figure 6. Photo of the Common Research Model in the National Transonic Facility.



Figure 7. Photo of the Common Research Model in the Ames 11-ft Wind Tunnel. 

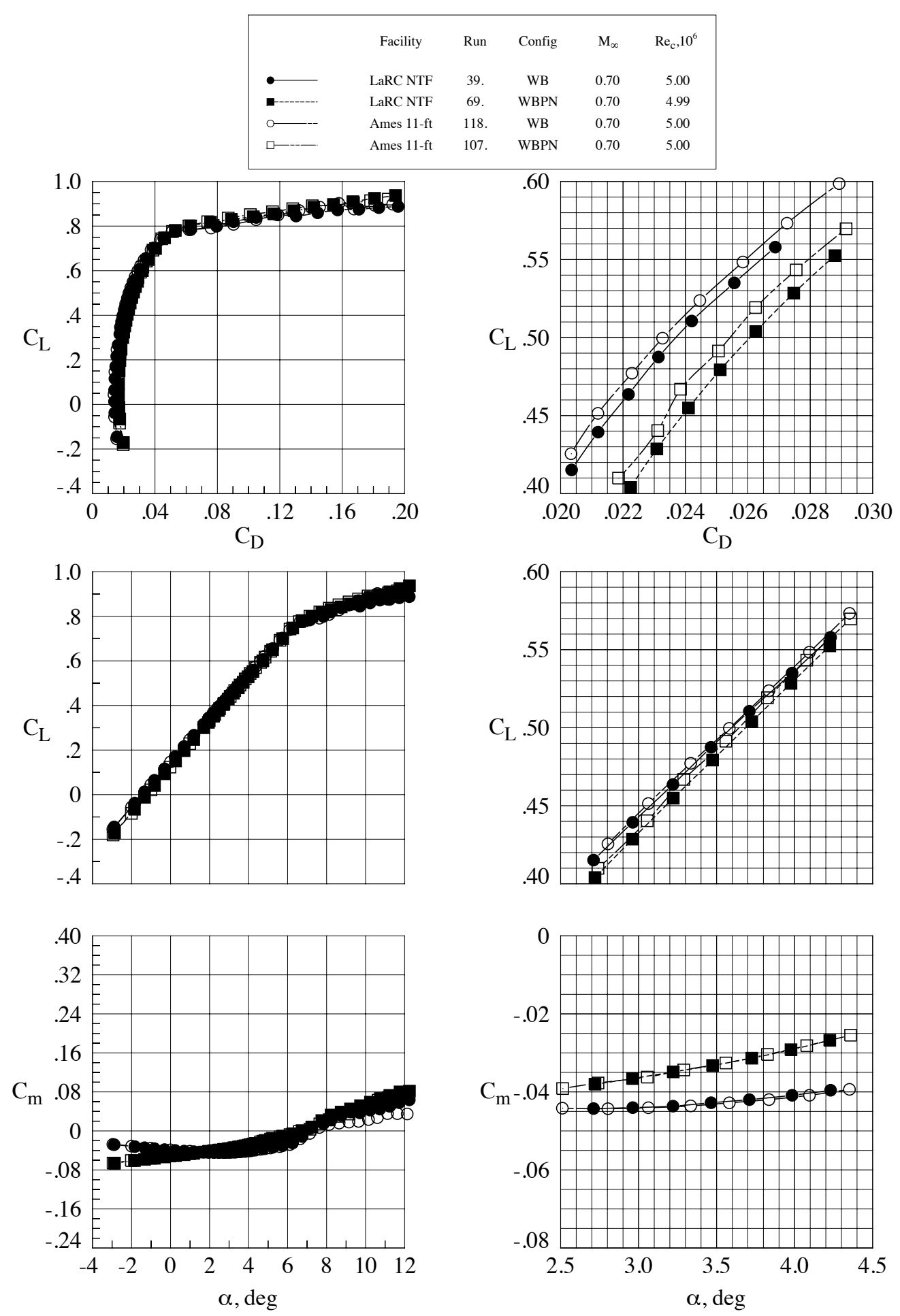

Figure 8. Pylon/Nacelle effects, $\operatorname{Mach}=0.7, \operatorname{Re}_{\mathrm{c}}=\mathbf{5 \times 1 0 ^ { 6 }}$. 


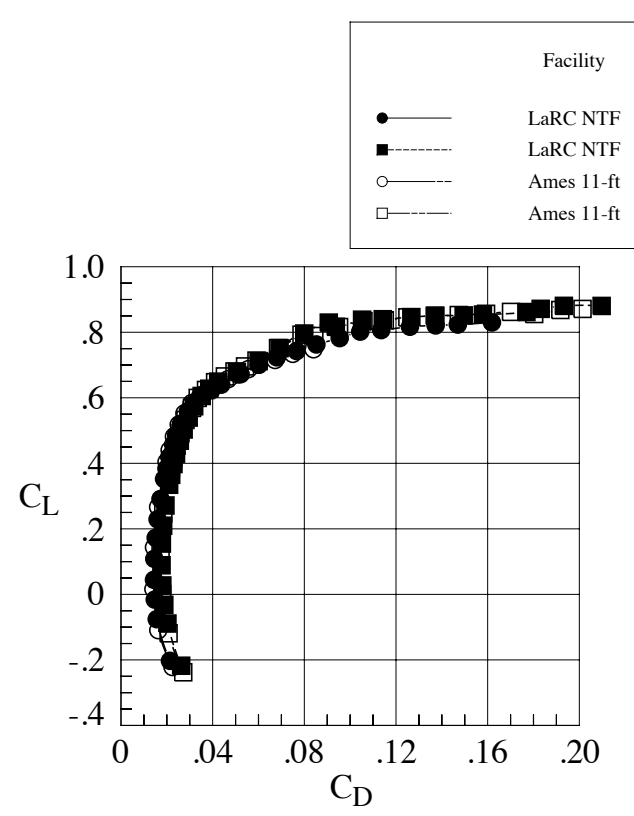

$\begin{array}{cccc}\text { Run } & \text { Config } & \mathrm{M}_{\infty} & \mathrm{Re}_{\mathrm{c}}, 10^{6} \\ \text { 44. } & \text { WB } & 0.85 & 4.99 \\ \text { 74. } & \text { WBPN } & 0.85 & 5.00 \\ \text { 126. } & \text { WB } & 0.85 & 5.00 \\ 108 . & \text { WBPN } & 0.85 & 5.00\end{array}$
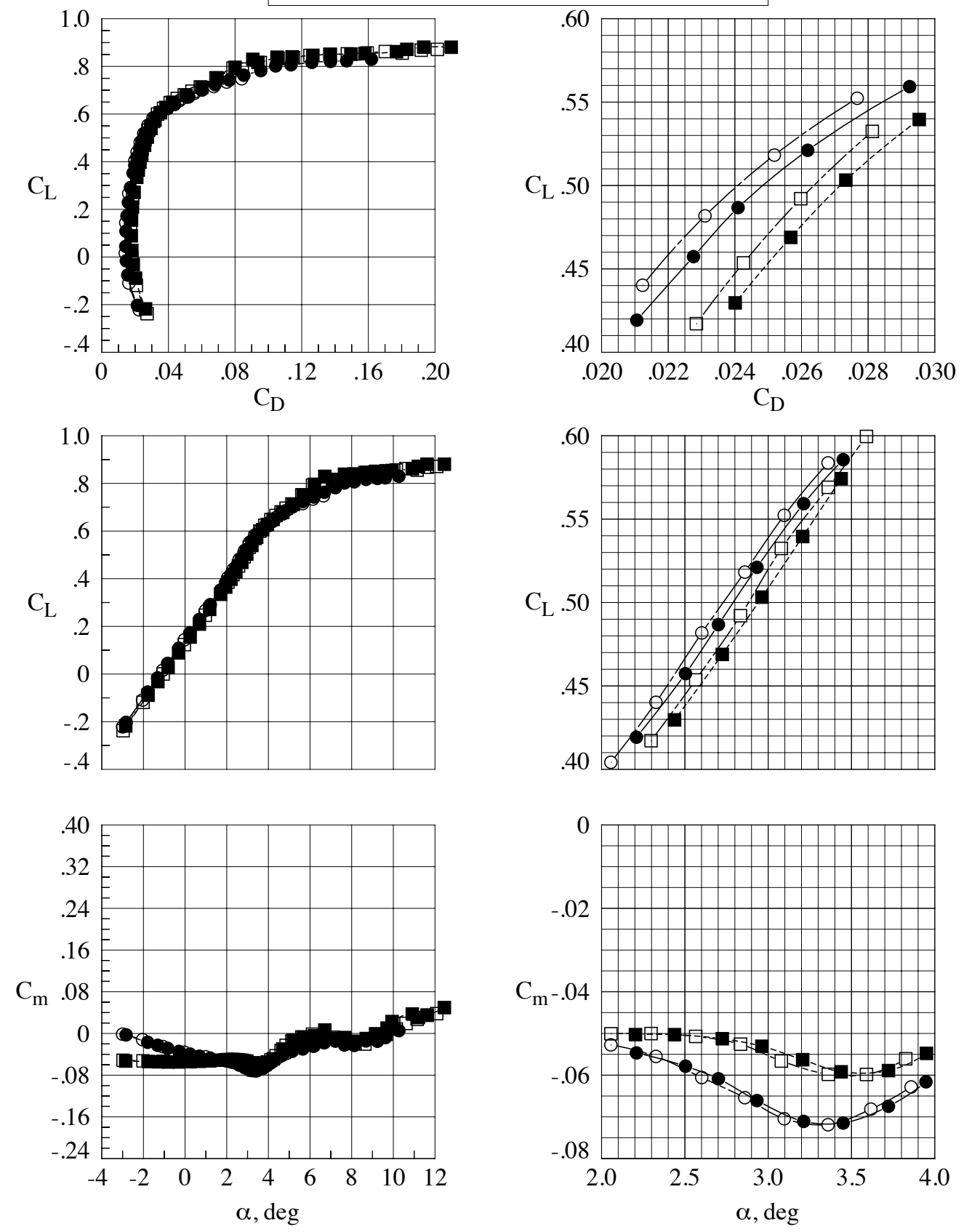

Figure 9. Pylon/Nacelle Effects, $M a c h=0.85, R_{c}=5 \times 10^{6}$. 


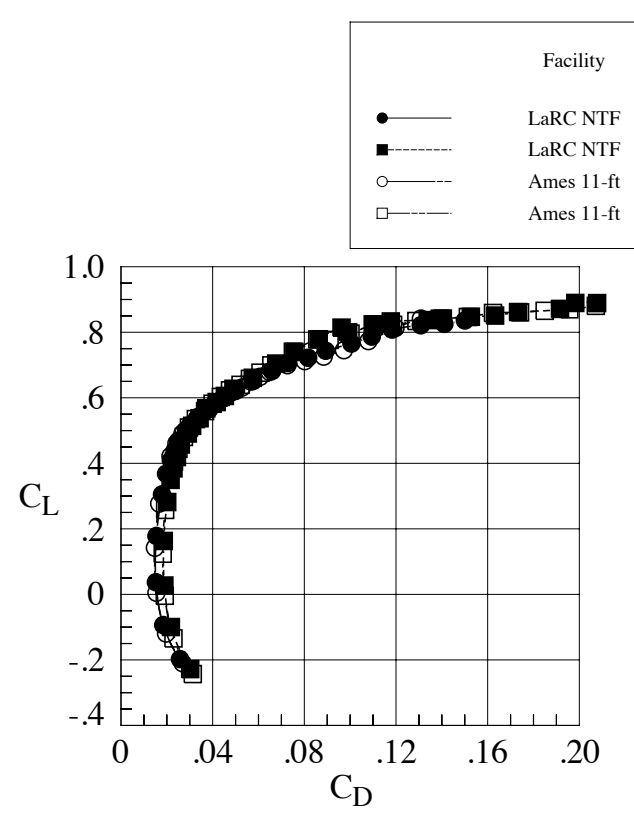

$\begin{array}{cccc}\text { Run } & \text { Config } & \mathrm{M}_{\infty} & \mathrm{Re}_{\mathrm{c}}, 10^{6} \\ \text { 47. } & \text { WB } & 0.87 & 5.00 \\ \text { 77. } & \text { WBPN } & 0.87 & 4.99 \\ \text { 131. } & \text { WB } & 0.87 & 5.00 \\ \text { 109. } & \text { WBPN } & 0.87 & 5.00\end{array}$


Figure 10. Pylon/Nacelle Effects, $\operatorname{Mach}=0.87, \operatorname{Re}_{c}=5 \times 10^{6}$. 


\begin{tabular}{|c|c|c|c|c|c|c|}
\hline & Facility & Run & Config & Tail $\angle$ & $\mathrm{M}_{\infty}$ & $\mathrm{Re}_{\mathrm{c}}, 10^{6}$ \\
\hline & LaRC NTF & 192. & WBT & $-2^{\circ}$ & 0.70 & 4.99 \\
\hline =-----. & LaRC NTF & 87. & WBT & $0^{\circ}$ & 0.70 & 5.00 \\
\hline$\bullet$ & LaRC NTF & 173. & WBT & $+2^{\circ}$ & 0.70 & 4.99 \\
\hline ○-_. & Ames $11-\mathrm{ft}$ & 85. & WBT & $-2^{\circ}$ & 0.70 & 5.00 \\
\hline 口---- & Ames 11-ft & 63. & WBT & $0^{\circ}$ & 0.70 & 5.00 \\
\hline$\diamond--$ & Ames 11-ft & 93. & WBT & $+2^{\circ}$ & 0.70 & 5.00 \\
\hline
\end{tabular}
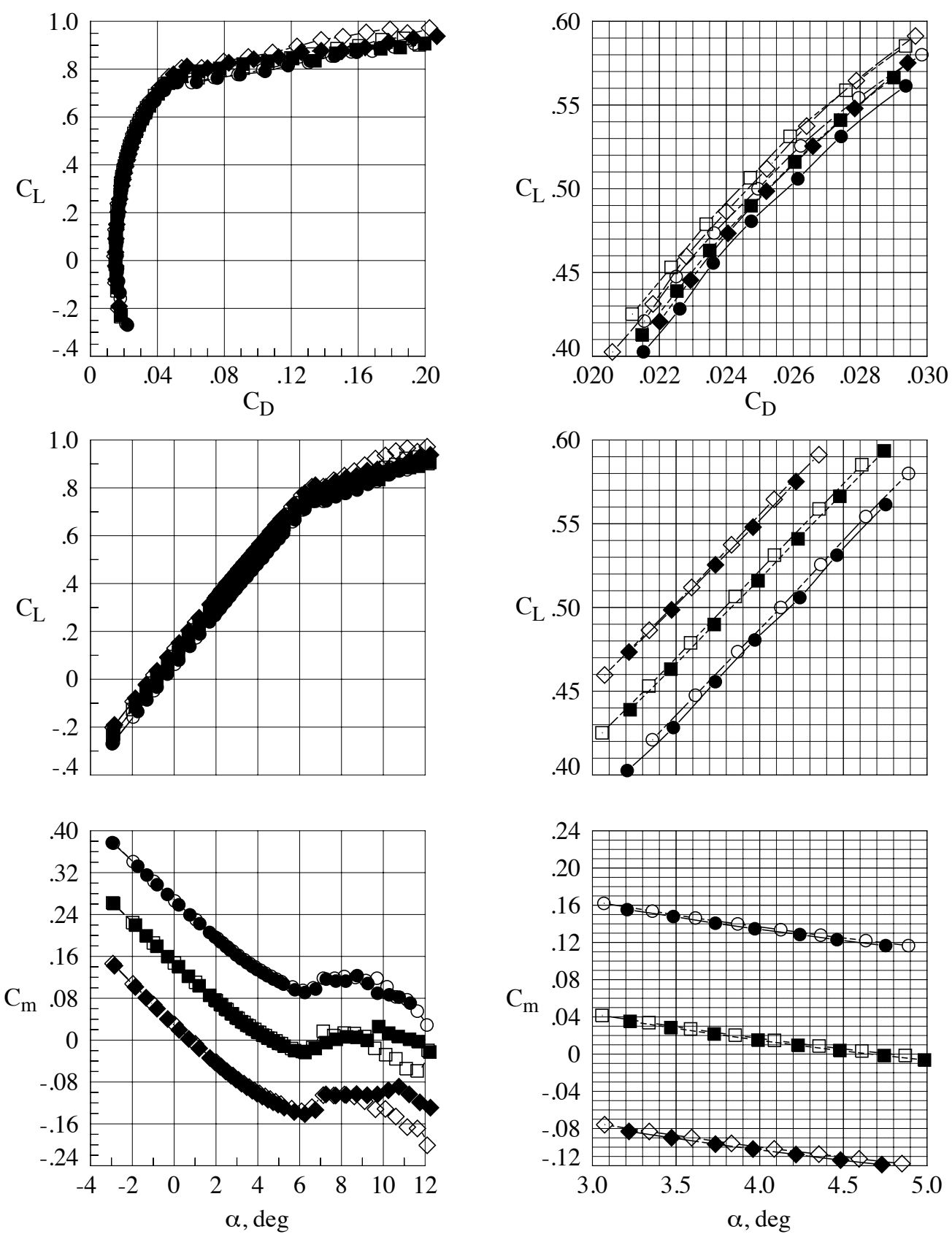

Figure 11. Tail Effects, $\operatorname{Mach}=0.7, \operatorname{Re}_{\mathrm{c}}=\mathbf{5 \times 1 0 ^ { 6 }}$ 


\begin{tabular}{|c|c|c|c|c|c|c|}
\hline & Facility & Run & Config & Tail $\angle$ & $\mathrm{M}_{\infty}$ & $\mathrm{Re}_{\mathrm{c}}, 10^{6}$ \\
\hline - & LaRC NTF & 196. & WBT & $-2^{\circ}$ & 0.85 & 4.99 \\
\hline - & LaRC NTF & 92. & WBT & $0^{\circ}$ & 0.85 & 5.00 \\
\hline$\bullet$ & LaRC NTF & 176. & WBT & $+2^{\circ}$ & 0.85 & 4.99 \\
\hline o--_. & Ames 11-ft & 86. & WBT & $-2^{\circ}$ & 0.85 & 5.00 \\
\hline 口--- & Ames 11-ft & 77. & WBT & $0^{\circ}$ & 0.85 & 5.00 \\
\hline$\diamond--$ & Ames $11-\mathrm{ft}$ & 94. & WBT & $+2^{\circ}$ & 0.85 & 5.00 \\
\hline
\end{tabular}
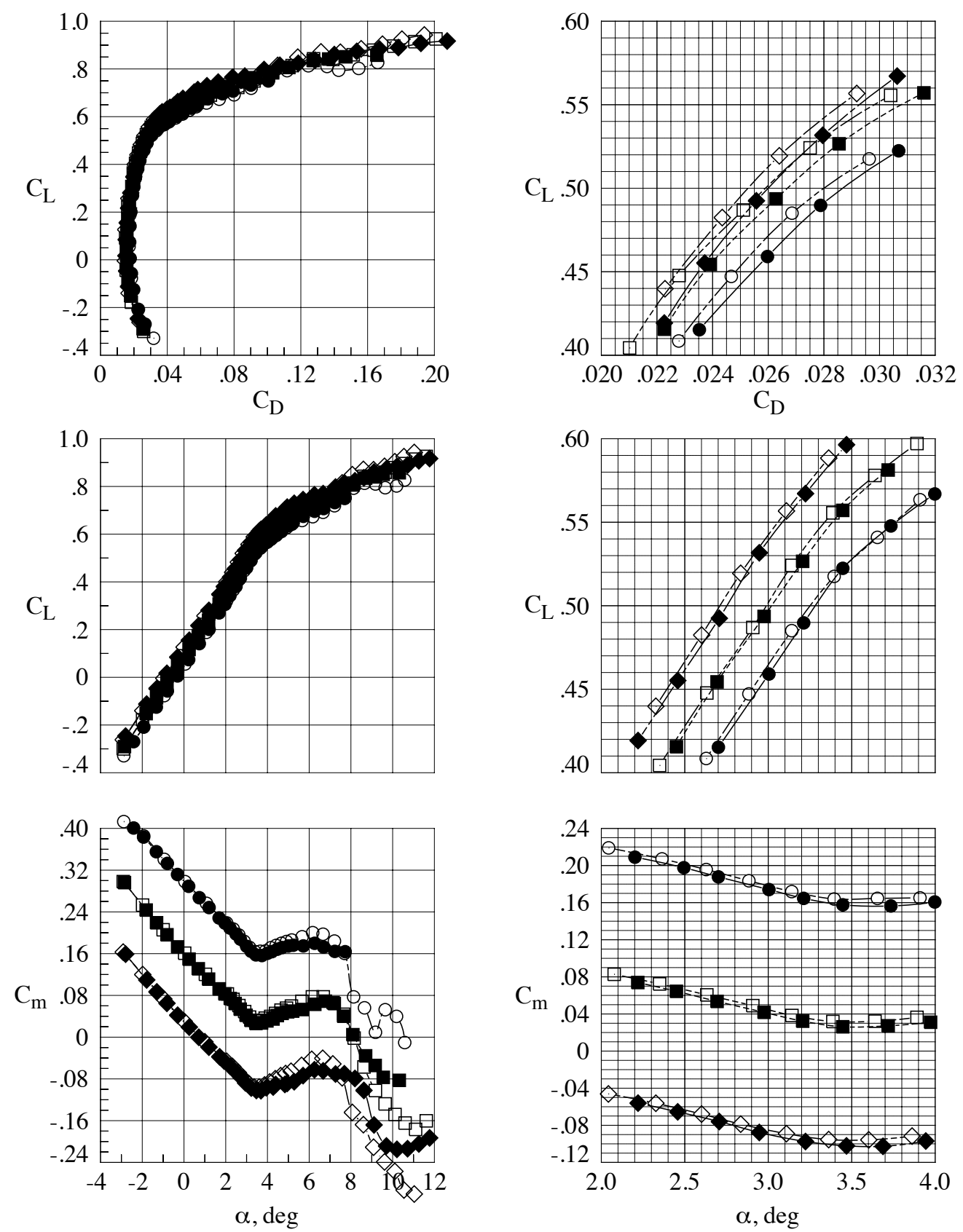

Figure 12. Tail Effects, $M a c h=0.85, \operatorname{Re}_{c}=5 \times 10^{6}$. 


\begin{tabular}{|c|c|c|c|c|c|c|}
\hline & Facility & Run & Config & Tail $\angle$ & $\mathrm{M}_{\infty}$ & $\mathrm{Re}_{\mathrm{c}}, 10^{6}$ \\
\hline & LaRC NTF & 198. & WBT & $-2^{\circ}$ & 0.87 & 4.99 \\
\hline =----.. & LaRC NTF & 95. & WBT & $0^{\circ}$ & 0.87 & 5.00 \\
\hline$\bullet$ & LaRC NTF & 178. & WBT & $+2^{\circ}$ & 0.87 & 4.99 \\
\hline 0 & Ames $11-\mathrm{ft}$ & 87. & WBT & $-2^{\circ}$ & 0.87 & 5.00 \\
\hline 口---- & Ames $11-\mathrm{ft}$ & 82. & WBT & $0^{\circ}$ & 0.87 & 5.00 \\
\hline$\diamond--$ & Ames 11-ft & 95. & WBT & $+2^{\circ}$ & 0.87 & 5.00 \\
\hline
\end{tabular}
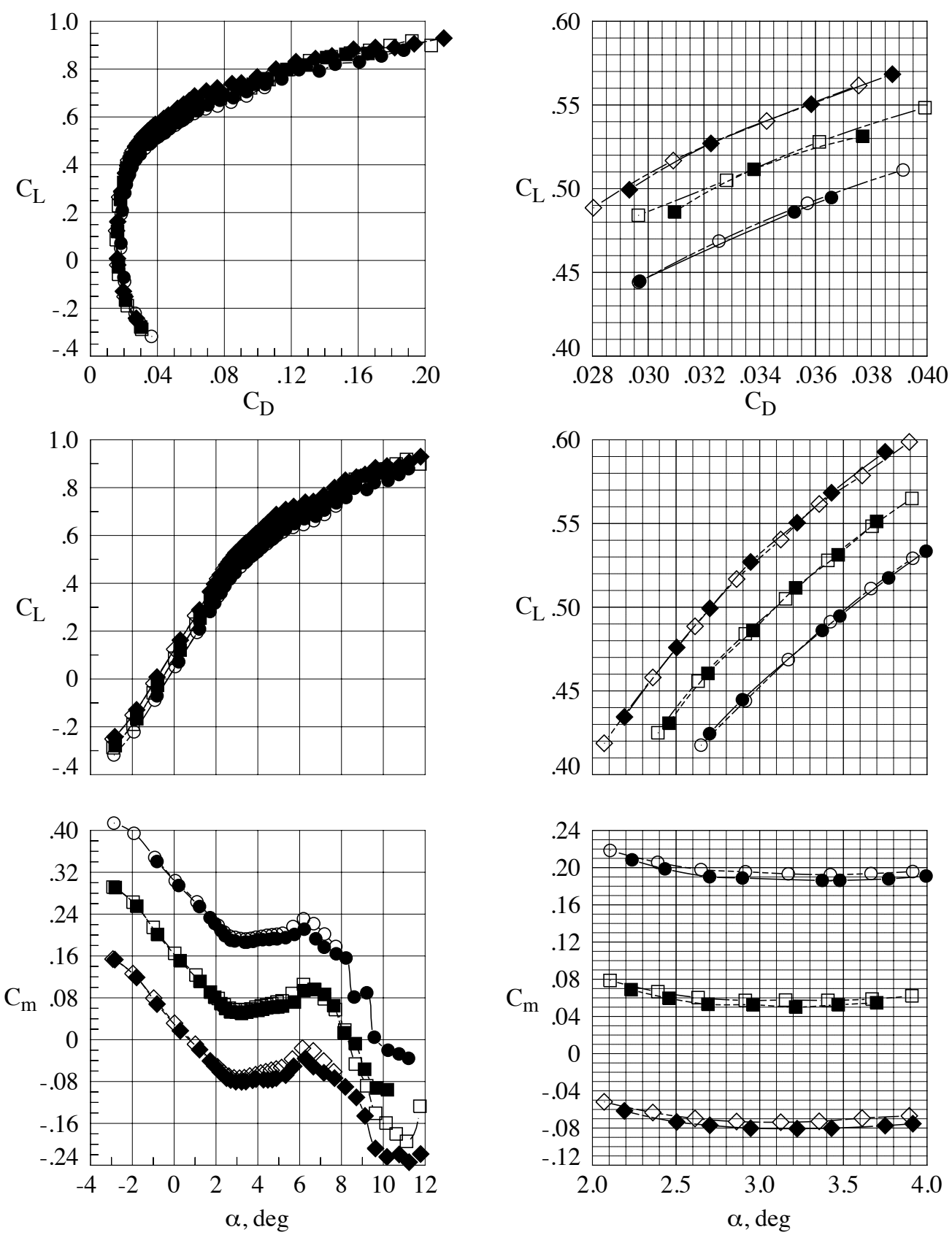

Figure 13. Tail Effects, $\operatorname{Mach}=0.87, \operatorname{Re}_{c}=5 \times 10^{6}$. 



Figure 14. NTF Data Repeatability, WB Configuration, $M a c h=0.85, \operatorname{Re}_{c}=5 \times 10^{6}$. Solid line indicates 2-sigma limits based on the residual data. 



Figure 15. Ames 11-ft Data Repeatability, WB Configuration, $M a c h=0.85, R_{c}=5 \times 10^{6}$. Solid line indicates 2-sigma limits based on the residual data. 

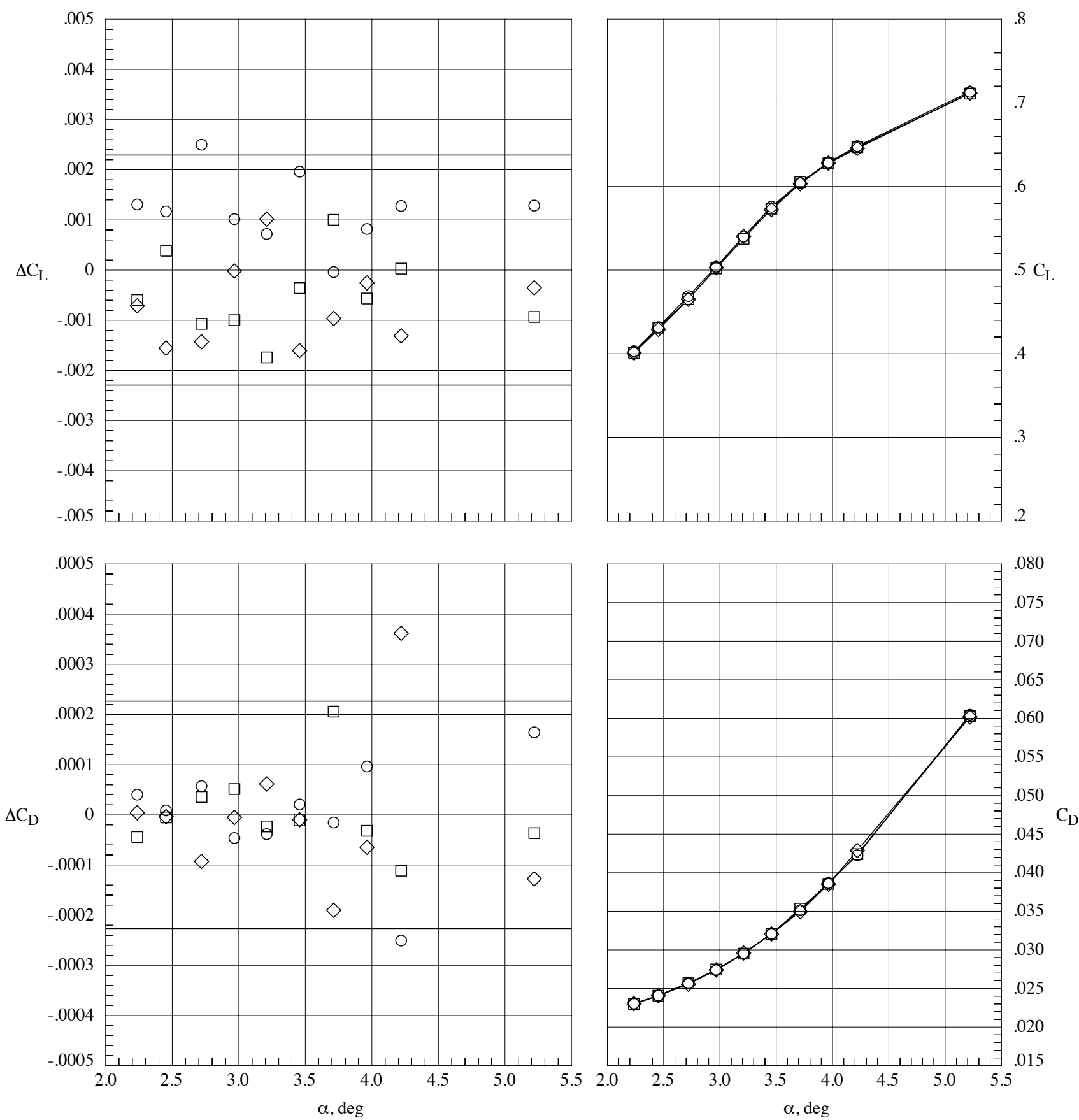

Figure 16. NTF Data Repeatability, WBPN Configuration, Mach $=0.85, \operatorname{Re}_{c}=5 \times 10^{6}$. Solid line indicates 2-sigma limits based on the residual data. 

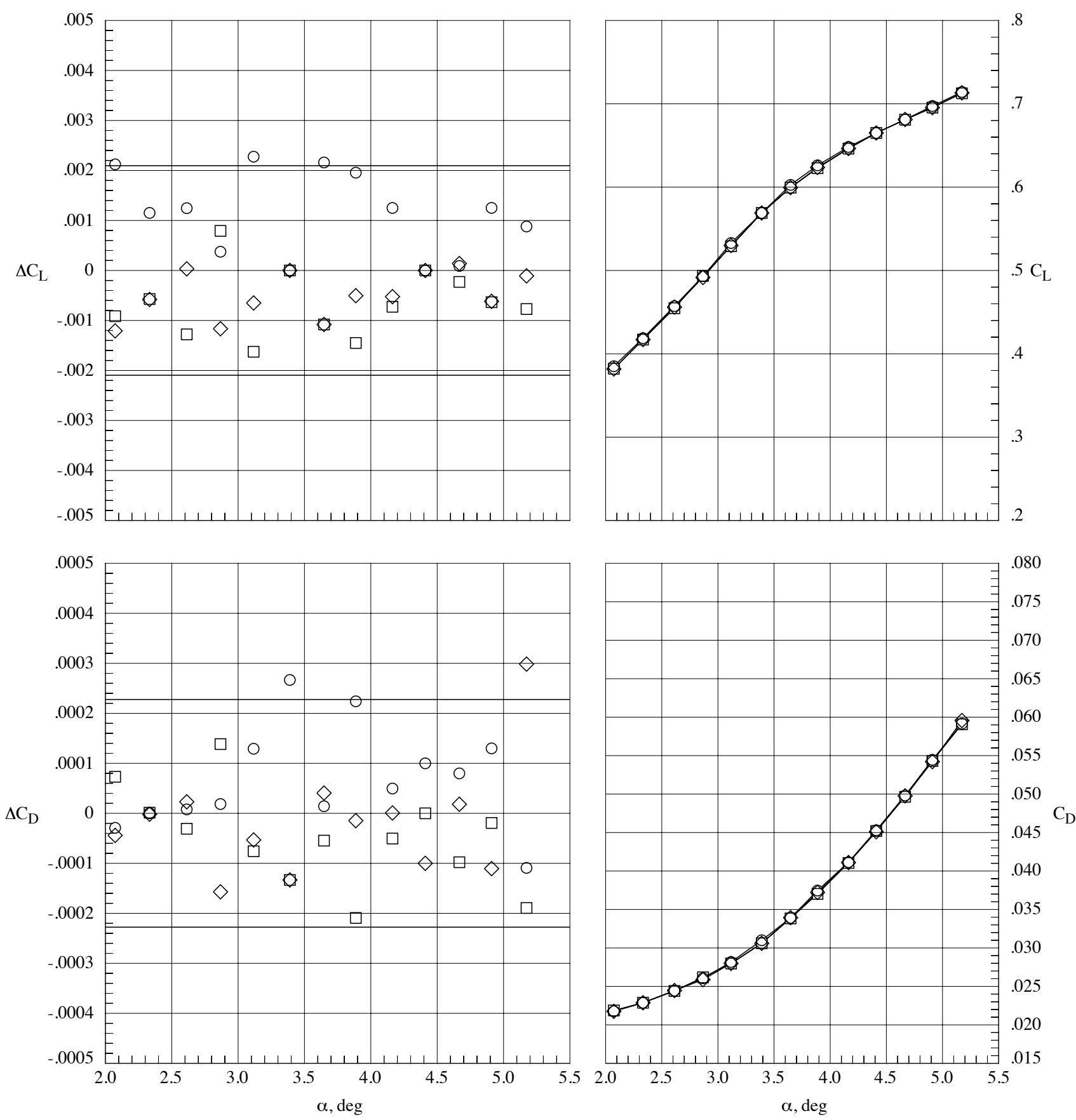

Figure 17. Ames 11-ft Data Repeatability, WBPN Configuration, $M a c h=0.85, \operatorname{Re}_{c}=5 \times 10^{6}$. Solid line indicates 2-sigma limits based on the residual data. 

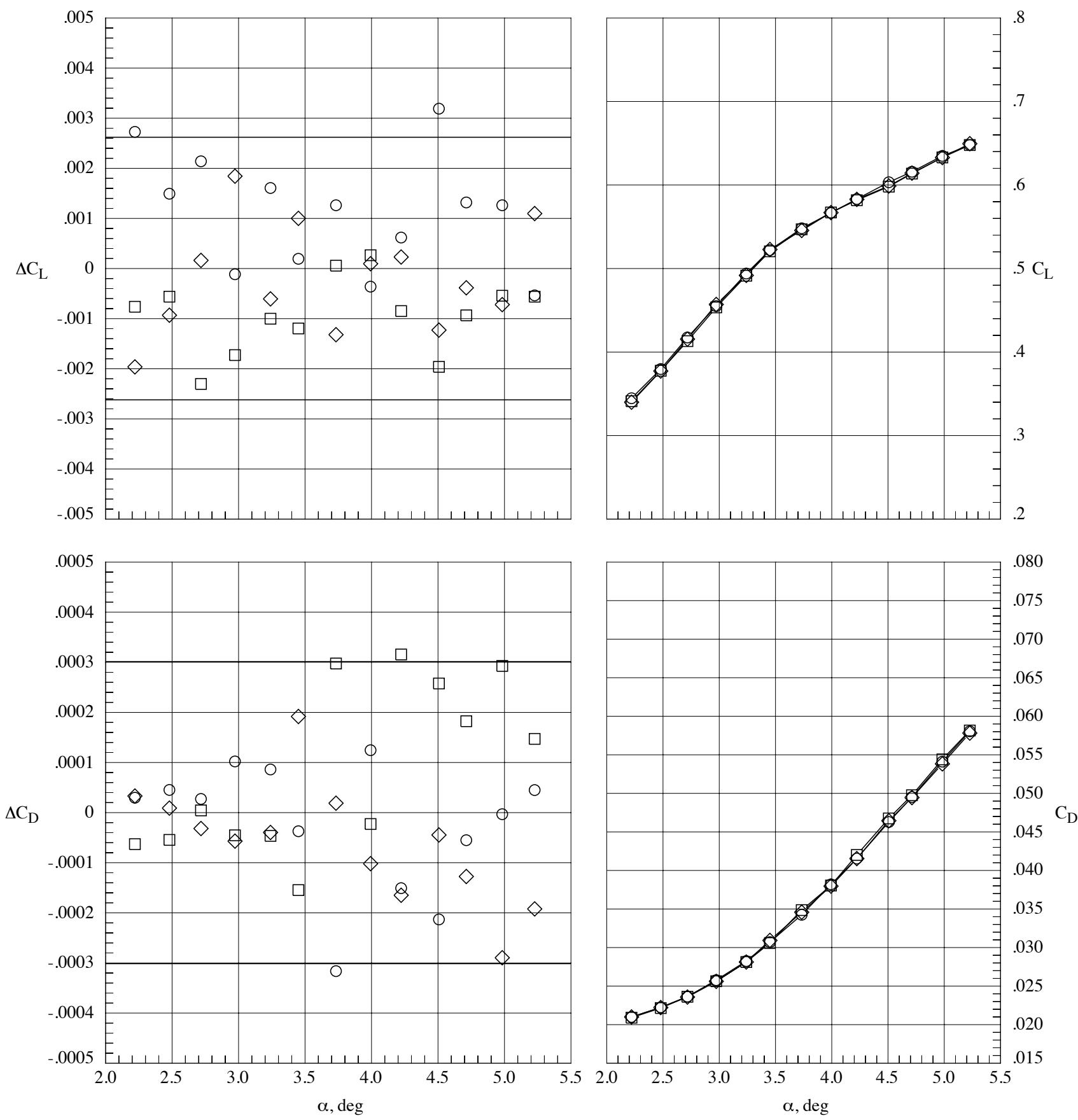

Figure 18. NTF Data Repeatability, WBT-2 Configuration, $M a c h=0.85, \operatorname{Re}_{c}=5 \times 10^{6}$. Solid line indicates 2-sigma limits based on the residual data. 

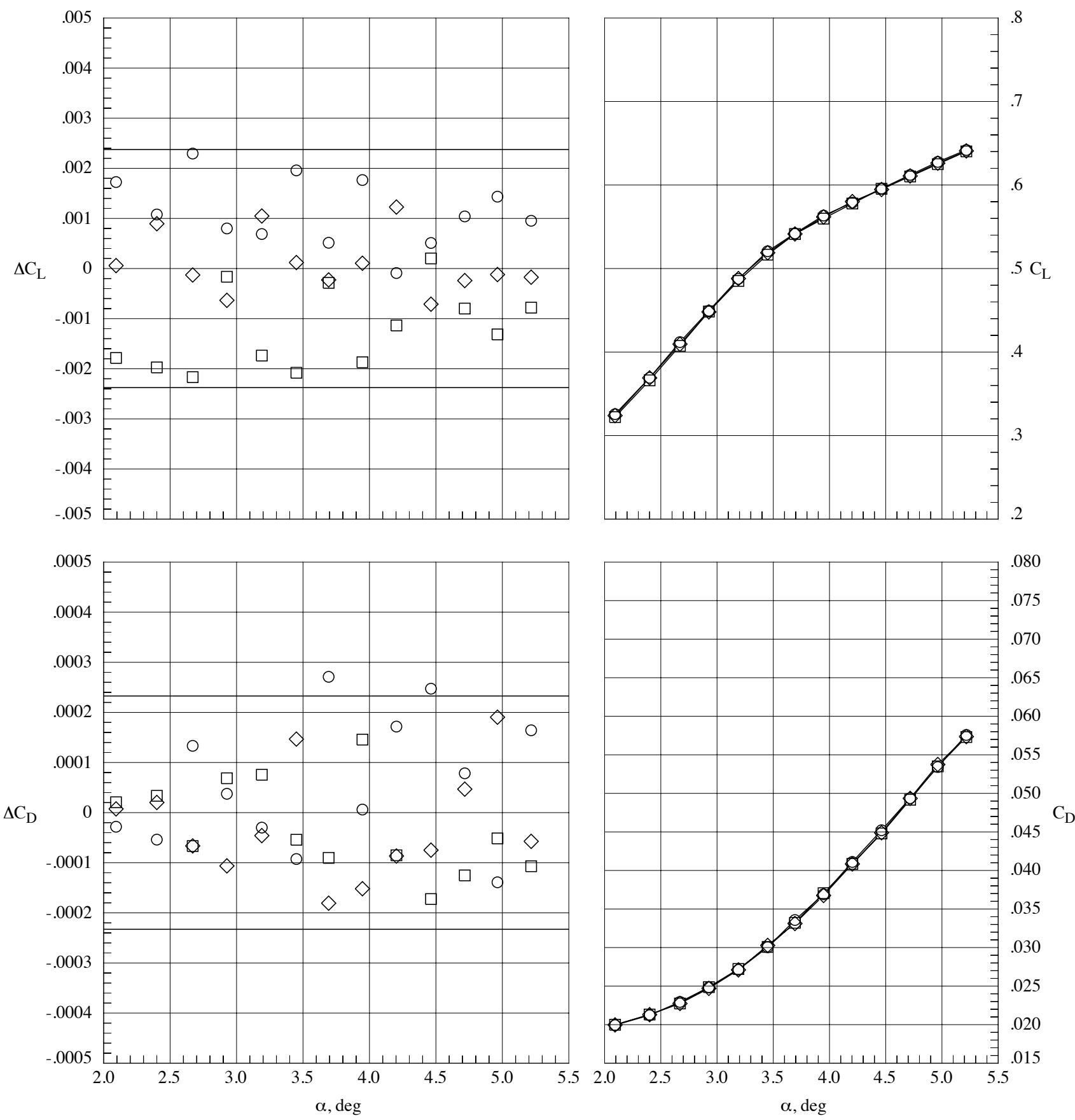

Figure 19. Ames 11-ft Data Repeatability, WBT-2 Configuration, $\operatorname{Mach}=0.85, \operatorname{Re}_{\mathrm{c}}=5 \times 10^{6}$. Solid line indicates 2-sigma limits based on the residual data. 

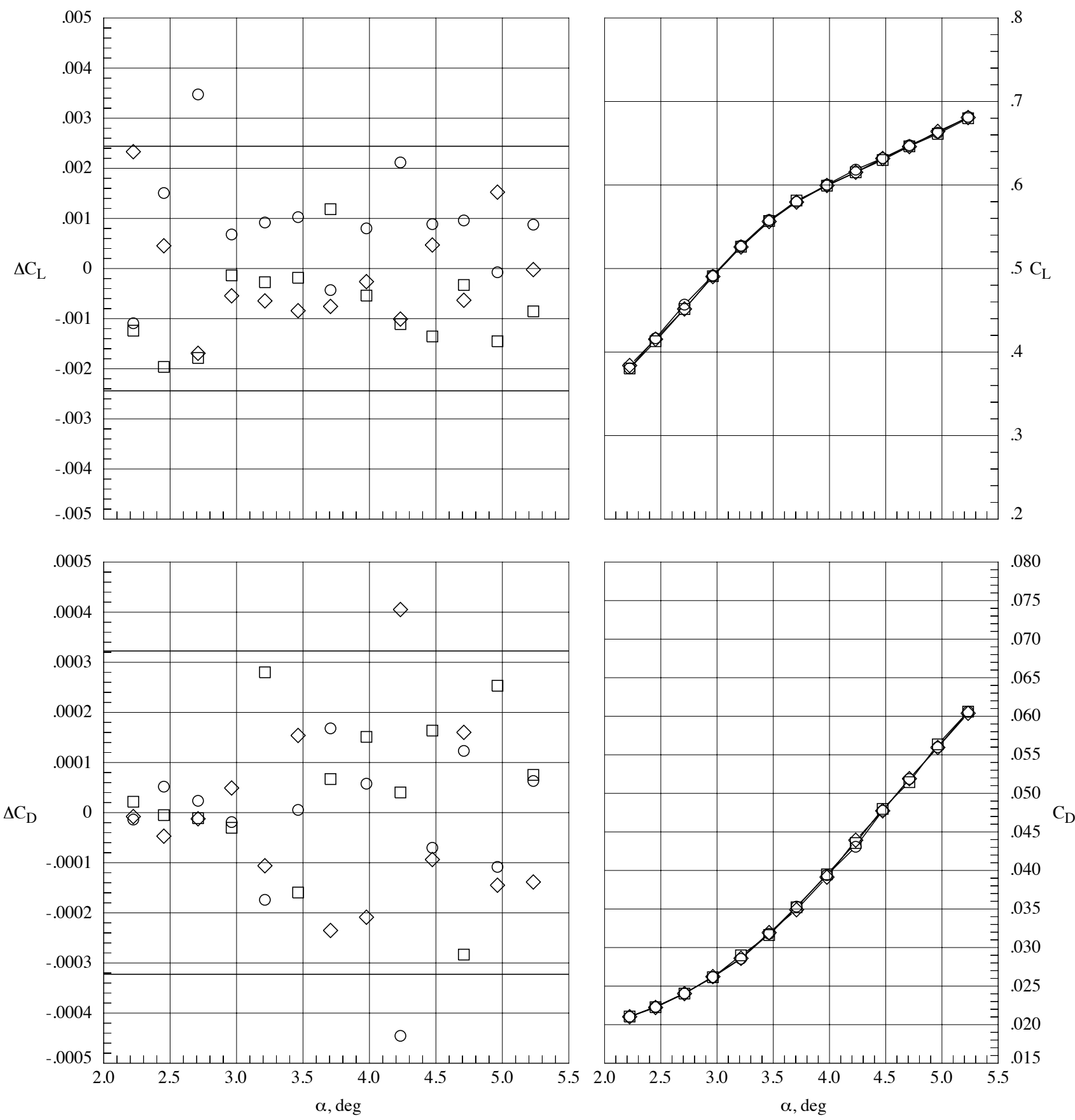

Figure 20. NTF Data Repeatability, WBT0 Configuration, $M a c h=0.85, \operatorname{Re}_{c}=5 \times 10^{6}$. Solid line indicates 2-sigma limits based on the residual data. 

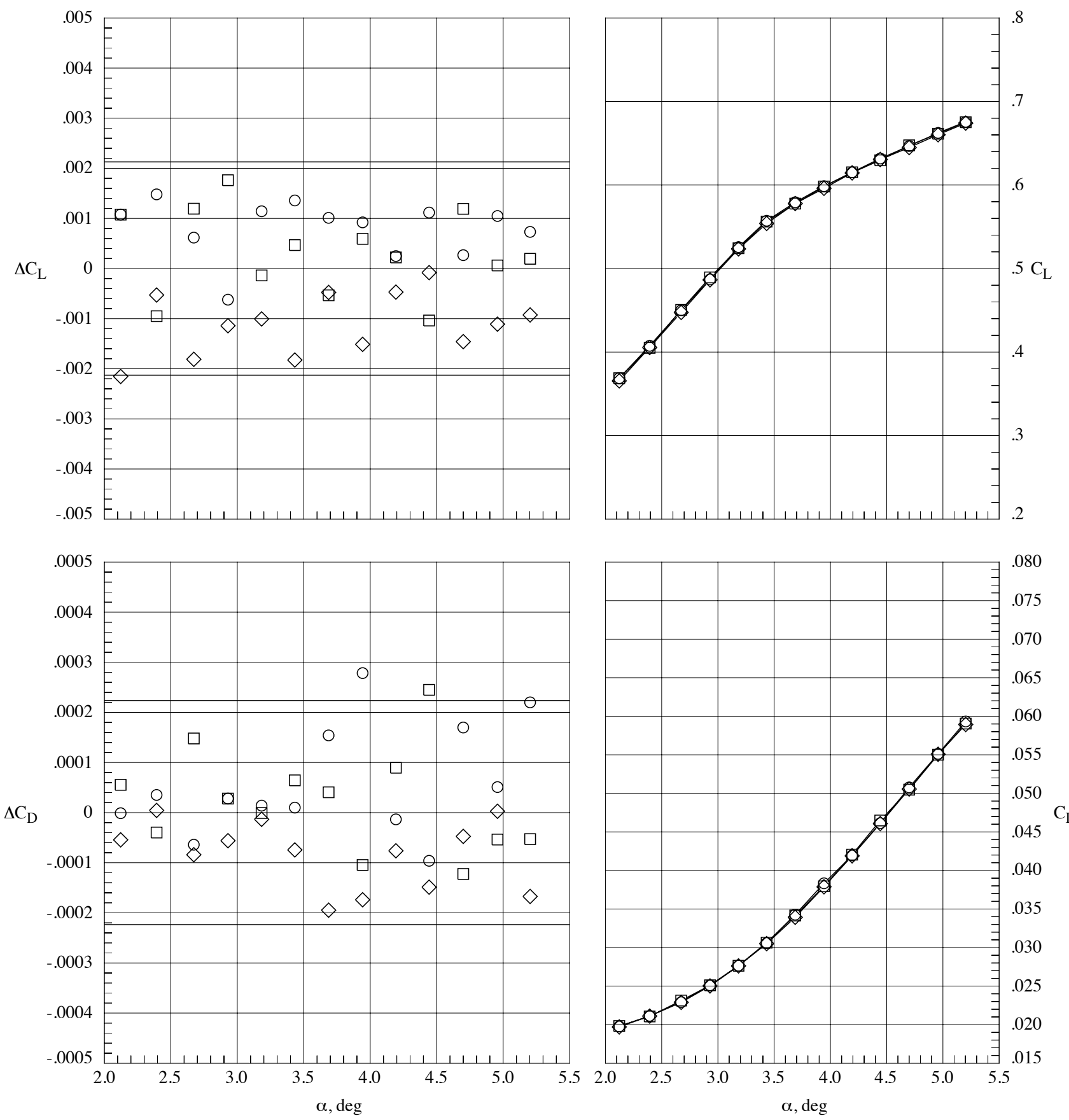

Figure 21. Ames 11-ft Data Repeatability, WBT0 Configuration, $M a c h=0.85, \operatorname{Re}_{c}=5 \times 10^{6}$. Solid line indicates 2-sigma limits based on the residual data. 

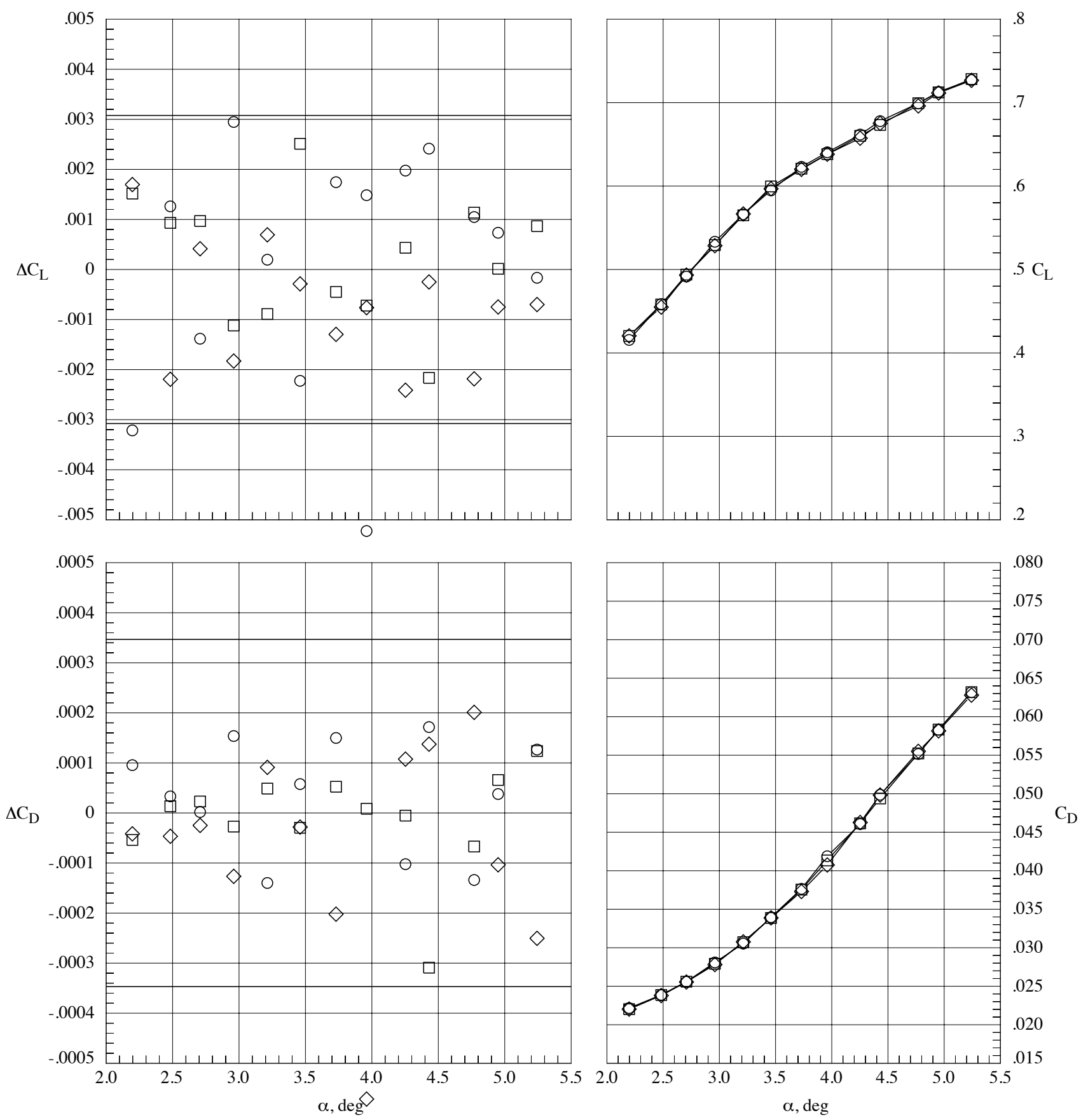

Figure 22. NTF Data Repeatability, WBT +2 Configuration, $M a c h=0.85, R_{c}=5 \times 10^{6}$. Solid line indicates 2-sigma limits based on the residual data. 

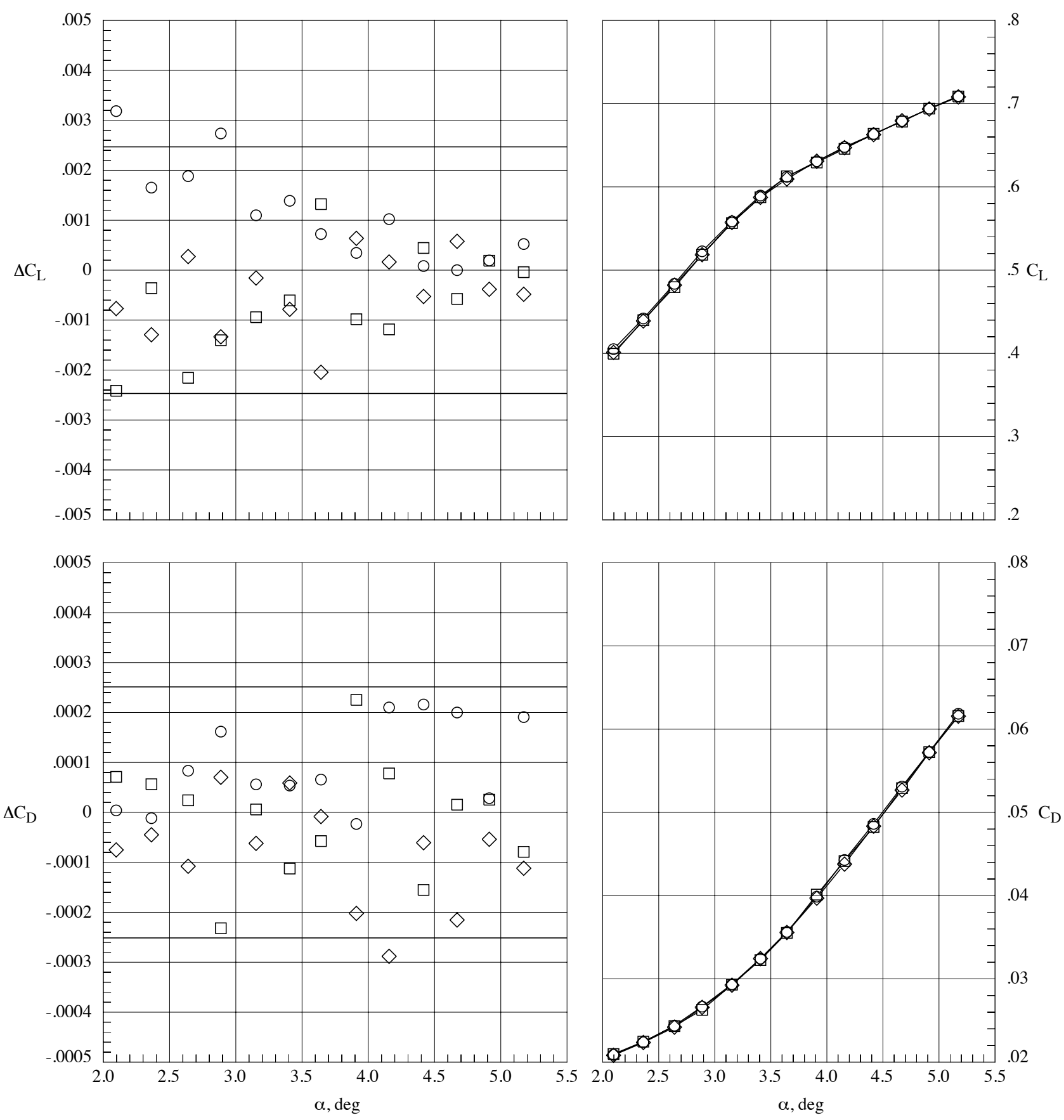

Figure 23. Ames 11-ft Data Repeatability, WBT+2 Configuration, $M a c h=0.85, \operatorname{Re}_{\mathrm{c}}=5 \times 10^{6}$. Solid line indicates 2-sigma limits based on the residual data. 